\title{
Influence of blinded wound closure on the volume stability of different GBR materials: an in vitro cone-beam computed tomographic examination. Part I
}

Mir-Mari, Javier ; Wui, Hu ; Jung, Ronald E ; Hämmerle, Christoph H F ; Benic, Goran I

\begin{abstract}
OBJECTIVE To test whether the use of (i) particulated bone substitute + collagen membrane used for guided bone regeneration (GBR) of peri-implant bone defects renders different results from (ii) particulated bone substitute + collagen membrane + fixation pins and from (iii) block bone substitute + collagen membrane with respect to the volume stability of the augmented region during suturing of mucosal flaps. MATERIAL AND METHODS Twenty peri-implant box-shaped bone defects were created in 10 pig mandibles. Every bone defect was augmented once with each of the following GBR procedures: Granulate (particulated xenograft + collagen membrane), Granulate + Pins (particulated xenograft + collagen membrane + fixation pins), and Block (block xenograft + collagen membrane). Cone-beam computed tomography scans were obtained prior and after blinded wound closure. The horizontal thickness (HT) of the augmented region (bone substitute + membrane) was assessed at the implant shoulder (HT0 mm ) and at 1-5 mm apical to the implant shoulder (HT1 mm -HT5 mm ). The changes of HT during flap suturing were calculated as absolute $(\mathrm{mm})$ and relative values (\%). Repeatedmeasures ANOVA was used for statistical analysis. RESULTS Wound closure induced a statistically significant change of HT0 mm and of HT1 mm in all the treatment groups $(\mathrm{P} \leq 0.05)$. The change in HT0 mm measured -42.8 $\pm 17.9 \%$ (SD) for Granulate, $-22.9 \pm 21.2 \%$ (SD) for Granulate + Pins, and $-20.2 \pm 18.9 \%$ (SD) for Block. The reduction in HT0 mm , HT1 mm , HT2 mm , and HT3 mm for the Granulate procedure was significantly higher as compared to the Granulate + Pins and the Block procedures $(\mathrm{P} \leq 0.05)$. There were no statistically significant differences in the change of HT between the Granulate + Pins and the Block procedures $(\mathrm{P}>0.05)$. CONCLUSION Wound closure induced displacement of the bone substitute resulting in a partial collapse of the collagen membrane in the coronal portion of the augmented site. The stability of the bone substitute and collagen membrane was enhanced by the application of fixation pins and by the use of block bone substitute instead of particulated bone substitute.
\end{abstract}

DOI: https://doi.org/10.1111/clr.12590

Posted at the Zurich Open Repository and Archive, University of Zurich

ZORA URL: https://doi.org/10.5167/uzh-110792

Journal Article

Accepted Version

Originally published at:

Mir-Mari, Javier; Wui, Hu; Jung, Ronald E; Hämmerle, Christoph H F; Benic, Goran I (2016). Influence of blinded wound closure on the volume stability of different GBR materials: an in vitro cone-beam computed tomographic examination. Part I. Clinical Oral Implants Research, 27(2):258-265.

DOI: https://doi.org/10.1111/clr.12590 


\title{
Influence of blinded wound closure on the volume stability of different GBR materials: an in vitro cone beam computed tomographic examination
}

\author{
Authors: \\ Mir-Mari, Javier ${ }^{1}$; Wui, Hu²; Jung, Ronald E. ${ }^{3}$; Hämmerle, Christoph H.F. ${ }^{3}$; Benic, \\ Goran I. ${ }^{3}$ \\ Authors' affiliations: \\ ${ }^{1}$ Oral Surgery and Implantology Department, Dental School, University of \\ Barcelona, Barcelona, Spain \\ ${ }^{2}$ Implant Center, School and Hospital of Stomatology, Peking University, Beijing, \\ China \\ ${ }^{3}$ Clinic of Fixed and Removable Prosthodontics and Dental Material Science, \\ Center of Dental Medicine, University of Zurich, Zurich, Switzerland
}

\section{Key words:}

bone, regeneration, alveolar ridge augmentation, guided bone regeneration, guided tissue regeneration, membrane, collagen, bone substitutes, graft, pin, tack, dental implants, cone-beam computed tomography, in vitro

\section{Running title:}

Volume stability of different GBR materials

\section{Corresponding author:}

Dr. Goran I. Benic

Clinic of Fixed and Removable Prosthodontics and Dental Material Science

Center of Dental Medicine

University of Zurich

Plattenstrasse 11

8032 Zurich, Switzerland

Tel: +416343252

Fax: +41446344305

E-mail: goran.benic@zzm.uzh.ch 


\section{Abstract}

Objective: To test whether the use of (1) particulated bone substitute + collagen membrane used for guided bone regeneration (GBR) of peri-implant bone defects renders different results from (2) particulated bone substitute + collagen membrane + fixation pins and from (3) block bone substitute + collagen membrane with respect to the volume stability of the augmented region during suturing of mucosal flaps.

Material and methods: Twenty peri-implant box-shaped bone defects were created in 10 pig mandibles. Every bone defect was augmented once with each of the following GBR procedures: Granulate (particulated xenograft + collagen membrane), Granulate + Pins (particulated xenograft + collagen membrane + fixation pins) and Block (block xenograft + collagen membrane). Cone beam computed tomography scans were obtained prior and after blinded wound closure. The horizontal thickness (HT) of the augmented region (bone substitute + membrane) was assessed at the implant shoulder $\left(\mathrm{HT}_{0 \mathrm{~mm}}\right)$ and at $1 \mathrm{~mm}$ to $5 \mathrm{~mm}$ apical to the implant shoulder $\left(\mathrm{HT}_{1 \mathrm{~mm}}-\mathrm{HT}_{5 \mathrm{~mm}}\right)$. The changes of $\mathrm{HT}$ during flap suturing were calculated as absolute $(\mathrm{mm})$ and relative values (\%). Repeated measures ANOVA were used for statistical analysis.

Results: Wound closure induced a statistically significant change of $\mathrm{HT}_{0 \mathrm{~mm}}$ and of $\mathrm{HT}_{1 \mathrm{~mm}}$ in all the treatment groups $(\mathrm{p} \leq 0.05)$. The change in $\mathrm{HT}_{0 \mathrm{~mm}}$ measured -42.8 $\pm 17.9 \%(\mathrm{SD})$ for Granulate, $-22.9 \pm 21.2 \%(\mathrm{SD})$ for Granulate + Pins and $-20.2 \pm$ $18.9 \%$ (SD) for Block. The reduction in $\mathrm{HT}_{0 \mathrm{~mm}}, \mathrm{HT}_{1 \mathrm{~mm}}, \mathrm{HT}_{2 \mathrm{~mm}}$ and $\mathrm{HT}_{3 \mathrm{~mm}}$ for the Granulate procedure was significantly higher as compared to the Granulate + Pins and the Block procedures ( $p \leq 0.05)$. There were no statistically significant differences in the change of HT between the Granulate + Pins and the Block procedures $(p>0.05)$

Conclusion: Wound closure induced displacement of the bone substitute resulting in a partial collapse of the collagen membrane in the coronal portion of the augmented site. The stability of the bone substitute and collagen membrane was enhanced by the application of fixation pins and by the use of block bone substitute instead of particulated bone substitute. 


\section{Introduction}

Edentulous jaw regions frequently present a reduced dimension of the alveolar ridge, either due to congenital or post-inflammatory defects or resulting from postextraction ridge resorption (Tan et al. 2012). The prosthetically driven implant placement is, therefore, often associated with the presence of peri-implant bone dehiscences and fenestrations.

Guided bone regeneration (GBR) is the best-documented method used to augment bone in localized alveolar defects (Benic \& Hämmerle 2014). A large number of preclinical and clinical trials demonstrated that exposed implant surfaces can successfully osseointegrate following GBR procedures (Kohal et al. 1999, Palmer et al. 1998, Warrer et al. 1991, Wilson et al. 1998, Becker et al. 1991). Moreover, there is a large body of clinical evidence documenting that survival rates of dental implants placed in conjuction with GBR are similar to survival rates of implants entirely placed into the native bone (Mayfield et al. 1998, Zitzmann et al. 2001, Benic et al. 2009, Zumstein et al. 2010, Jung et al. 2012).

The application of particulated deproteinized bovine-derived bone mineral (DBBM) covered with resorbable collagen membrane is, currently, the most widely used and best documented method for augmentation of dehiscence- and fenestration-type bone defects (Chiapasco et al. 2009, Jensen \& Terheyden 2009). DBBM and native collagen membranes exhibit good tissue integration, rendering high clinical success and low complications rates of the GBR procedures (Benic \& Hämmerle 2014). However, major drawback of particulated grafting materials and collagen membranes may be caused by their unfavourable mechanical properties with poor resistance to collapse. While suturing the mucosal flap or during the healing phase, compressive forces at the augmented site may result in membrane collapse and displacement of parts of the grafting material (Mellonig et al. 1998, Schwarz et al. 2007, Strietzel et al. 2006, Zellin et al. 1995).

Some publications pointed out that the volume stability of sites that are augmented by GBR may be affected by properties of the grafting material and of the membrane, by use of pins for the stabilization of membranes, by flap manipulation and type of temporary restoration (Von Arx et al. 2001, Carpio et al. 2000, Zitzmann \& Marinello 1999, Lorenzoni et al. 1998). There is, however, limited evidence available on the short- and the long-term three-dimensional changes of jaw regions augmented by means of GBR (Benic \& Hämmerle 2014). 
The primary aim of the present study was to test whether the flap suturing following GBR of peri-implant bone defects by using xenografts and collagen membranes induces, as assessed by means of cone-beam computed tomography $(\mathrm{CBCT})$, a displacement of the grafting material. In addition, it was tested whether the use of (1) particulated bone substitute + collagen membrane renders different results from (2) particulated bone substitute + collagen membrane + fixation pins and from (3) block bone substitute + collagen membrane with respect to the volume stability of the augmented region during suturing of mucosal flaps. 


\section{Material and methods}

Two clinicians performed the experimental surgical interventions. The first operator created the peri-implant defects and performed GBR. The second clinician, that was unaware of the treatment strategy used for GBR and of the aim of the study, provided the wound closure, in order to eliminate operator's bias.

\section{In vitro model}

Ten mandibles were obtained from five month old pigs. Crestal incisions were bilaterally performed mesial to the second premolars and one vertical releasing incision was made at the disto-buccal aspect of each second premolar. Mucoperiosteal flaps were elevated, second premolars were hemi-sectioned and their mesial roots were extracted. Twenty box-shaped bone defects, one at each extraction site, were prepared by means of cylindrical carbide drills. The bone defects measured $8 \mathrm{~mm}$ mesio-distally, $3 \mathrm{~mm}$ bucco-orally and $6 \mathrm{~mm}$ apicocoronally (Fig. 1). One $8 \mathrm{~mm}$-length and $4 \mathrm{~mm}$-diameter titanium implant (OsseoSpeed $^{\mathrm{TM}}$ S, ASTRA TECH Implant System, DENTSPLY Implants, Mannheim, Germany) was inserted into each bone defect by placing the implant central axis along the lingual bone wall at the same distance from the mesial and the distal walls of the defect. The apico-coronal position of the implant shoulder corresponded to the most coronal part of the lingual bone wall. The distance between the implant surface and the most buccal aspect of the apical bone wall, in a direction perpendicular to the axis of the implant, measured $1 \mathrm{~mm}$ (Fig. 1).

\section{GBR and wound closure}

Prior to GBR, bone substitute materials were soaked in $50 \%$ aqueous solution of a radio-opaque contrast medium (Gastrografin ${ }^{\circledR}$, Bayer, Zurich, Switzerland).

Every bone defect $(n=20)$ was augmented once for each GBR procedure under investigation. The sequence of the application was randomly assigned by casting a die.

The following GBR procedures were tested (Fig. 2): 
- Granulate: Particulated Demineralized Bovine Bone Mineral (DBBM) (BioOss ${ }^{\circledR}$ granules 0.25-1 mm, Geistlich Pharma AG, Wolhusen, Switzerland) + collagen membrane (Bio-Gide ${ }^{\circledR}$, Geistlich Pharma AG) $(n=20)$

- Granulate + Pins: Particulated DBBM (Bio-Oss ${ }^{\circledR}$ granules 0.25-1 mm, Geistlich Pharma AG) + collagen membrane (Bio-Gide ${ }^{\circledR}$, Geistlich Pharma $A G)+$ two titanium fixation pins (Frios ${ }^{\circledR}$, DENTSPLY Implants) $(n=20)$

- Block: Block DBBM (Bio-Oss ${ }^{\circledR}$ block, Geistlich Pharma AG) + collagen membrane (Bio-Gide ${ }^{\circledR}$, Geistlich Pharma AG) $(n=20)$

Bone substitutes were applied aiming to achieve $1 \mathrm{~mm}$ of over-contour with respect to the buccal surface of the alveolar ridge. A customized silicone guide was used to enable the application of a standardized amount of grafting material. For Block procedure, a block DBBM was individually shaped and adapted to fit the bone defect by using cylindrical carbide drills. The collagen membrane was applied to cover the bone substitute and overlap the walls of the defect by at least $2 \mathrm{~mm}$. For Granulate + Pins procedure, two titanium pins were placed $1 \mathrm{~mm}$ apically to the apical wall of the defect in order to stabilize the collagen membrane (Fig. 2).

A periosteal release incision was performed in the apical portion of the buccal mucoperiosteal flap. The flaps were sutured with a polyamid monofilament suture (Dafilon ${ }^{\circledR}$ 5-0, B. Braun Medical AG, Sempach, Switzerland). One operator, that was unaware of the treatment strategy used for GBR, performed the suturing procedure in a standardized way (one horizontal mattress and four single interrupted sutures per site) (Fig 2).

Prior to the subsequent GBR procedure, the sutures, the membrane, the pins and the bone substitute were removed and the experimental site was rinsed with a $0.9 \%$ saline solution.

\section{CBCT scanning}

CBCT scans (I-Cat ${ }^{\circledR}, \mathrm{KaV}$ Dental $\mathrm{GmbH}$, Biberach, Germany) of the mandible were performed immediately prior and after the flap suturing at each site. For the scanning procedure, the jaws were positioned on the supporting plate provided by the manufacturer with the occlusal plane parallel to the horizontal plane and positioned in the centre of field of view (FOV) using the laser orientation beams. The СВCT scans were obtained with the following technical parameters: $120 \mathrm{kV}$ acceleration voltage, $5 \mathrm{~mA}$ beam current, FOV diameter of $16 \mathrm{~cm}$, FOV height of 6 
$\mathrm{cm}, 600$ projections, $360^{\circ}$ rotation, voxel size of $0.25 \mathrm{~mm}$ and scan time of 14.7 seconds (Benic et al. 2013).

\section{CBCT image evaluation}

OsiriX ${ }^{\mathrm{TM}}$ imaging software (OsiriX v.4.0 32-bit, Pixmeo SARL, Bernex, Switzerland) was used for the evaluation of the CBCT DICOM datasets. "Full dynamic" visualization modality was used to set the window level (3084) and window width (8168). Cross-sectional images perpendicular to the implant central axis and mandibular panoramic curve were used for the measurements. The horizontal thickness of the augmented region (bone substitute + membrane) was assessed in a direction perpendicular to the implant surface at the implant shoulder $\left(\mathrm{HT}_{\mathrm{Omm}}\right)$ and at $1 \mathrm{~mm}, 2 \mathrm{~mm}, 3 \mathrm{~mm}, 4 \mathrm{~mm}$ and $5 \mathrm{~mm}$ apical to the implant shoulder $\left(\mathrm{HT}_{1 \mathrm{~mm}}\right.$ - $\mathrm{HT}_{5 \mathrm{~mm}}$ ) (Fig. 3). To facilitate the reproducibility of the measurements, a transparent acetate foil with printed implant outlines and levels for the assessment of $\mathrm{HT}$ was placed on the computer monitor over the CBCT images (Benic et al 2013).

The presence of void spaces within the augmented area was assessed to describe the fit of the bone substitute to the bone defect. Void spaces were defined as radiolucent regions within the augmented area with a diameter $\geq 0.5 \mathrm{~mm}$. One calibrated investigator performed all the CBCT measurements.

\section{Data analysis}

The changes of HT during flap suturing were calculated as absolute $(\mathrm{mm})$ and relative values (\%) (SPSS version 20, IBM, Armonk, USA).

Descriptive statistics were computed for all the parameters. For continuous parameters, the data distributions were represented with barplots and boxplots. The data were reported by using means, standard deviations (SD) and 95\% confidence intervals (CI). The assumption of normality was controlled by Kolmogorov-Smirnov and Shapiro-Wilk tests. All the results, with exception of $\mathrm{HT}_{5 \mathrm{~mm}}$ in the Block group, presented a normal distribution. For discrete variables, the absolute and the relative frequencies were calculated.

Repeated measures ANOVA were applied to detect differences of HT before suturing and differences of the changes in HT between the treatment procedures. The 
Greenhouse-Geisser correction was performed when Mauchly's test ruled out sphericity. Results of tests with $p$-values $\leq 0.05$ were considered statistically significant. In case of non-normal data distribution, non-parametric paired Wilcoxon test with Bonferroni correction of the significance level was applied to test differences between the treatment procedures. Results of tests with $p$-values $\leq$ $0.05 / 3=0.016$ were considered statistically significant.

Two weeks after the CBCT image analysis, 10 randomly selected $\mathrm{CBCT}$ images were re-assessed to test the intra-observer reliability of CBCT measurements. The intraclass correlation coefficient (ICC) for $\mathrm{HT}_{0 \mathrm{~mm}}-\mathrm{HT}_{5 \mathrm{~mm}}$ ranged from 0.973 to 0,989 (95\% CI: 0,932-0,996), indicating high intra-examiner agreement. 


\section{Results}

There were no statistically significant differences in HT before suturing between the treatment procedures $(p=0.276)$ (Table $1 a)$. Suturing of mucosal flaps induced a statistically significant change in HT ( $p=0.001)$ (Table $1 \mathrm{~b})$. The differences in the change of HT between the GBR procedures reached statistical significance ( $p<$ 0.001) (Table 1b).

The results of HT before and HT after suturing and the change in HT for different GBR procedures are presented in Tables 2 and 3 and Figures 4 and 5 . The change in $\mathrm{HT}_{0 \mathrm{~mm}}$ measured $-42.8 \pm 17.9 \%$ (SD) for Granulate, $-22.9 \pm 21.2 \%$ (SD) for Granulate + Pins group and $-20.2 \pm 18.9 \%$ (SD) for Block. The alteration of $\mathrm{HT}_{1 \mathrm{~mm}}$ amounted to $-23.4 \pm 11.9 \%$ (SD) for Granulate, $-6.9 \pm 12.5 \%$ (SD) for Granulate + Pins and $-10.8 \pm 13.2 \%(S D)$ for Block. The reductions of $\mathrm{HT}_{0 \mathrm{~mm}}$ and of $\mathrm{HT}_{1 \mathrm{~mm}}$ were statistically significant in all the treatment groups (Granulate $\mathrm{HT}_{0 \mathrm{~mm}}, \mathrm{p}<$ 0.001; Granulate $\mathrm{HT}_{1 \mathrm{~mm}}, \mathrm{p}<0.001$; Granulate + Pins $\mathrm{HT}_{0 \mathrm{~mm}}, \mathrm{p}<0.001$; Granulate + Pins $\mathrm{HT}_{1 \mathrm{~mm}}, \mathrm{p}=0.012$; Block $\mathrm{HT}_{0 \mathrm{~mm}}, \mathrm{p}<0.001$, Block $\mathrm{HT}_{1 \mathrm{~mm}}, \mathrm{p}=0.002$ ). The reduction of $\mathrm{HT}_{2 \mathrm{~mm}}$ reached statistical significance for Granulate and Block (Granulate $\mathrm{HT}_{2 \mathrm{~mm}}, \mathrm{p}<0.001$; Block $\mathrm{HT}_{2 \mathrm{~mm}}, \mathrm{p}=0.05$ ). The reduction of $\mathrm{HT}_{3 \mathrm{~mm}}$ and of $\mathrm{HT}_{4 \mathrm{~mm}}$ was statistically significant only for Granulate (Granulate $\mathrm{HT}_{3 \mathrm{~mm}}, \mathrm{p}<$ 0.001; Granulate $\mathrm{HT}_{4 \mathrm{~mm}}, \mathrm{p}=0.012$ ) (Table 2 and Fig. 4).

The differences in the changes of $\mathrm{HT}_{0 \mathrm{~mm}}, \mathrm{HT}_{1 \mathrm{~mm}}, \mathrm{HT}_{2 \mathrm{~mm}}$ and $\mathrm{HT}_{3 \mathrm{~mm}}$ between Granulate and Granulate + Pins $\left(\mathrm{HT}_{0 \mathrm{~mm}}, \mathrm{p}<0.001 ; \mathrm{HT}_{1 \mathrm{~mm}}, \mathrm{p}<0.001 ; \mathrm{HT}_{2 \mathrm{~mm}}, \mathrm{p}=\right.$ $\left.0.001 ; \mathrm{HT}_{3 \mathrm{~mm}}, \mathrm{p}=0.007\right)$ and between Granulate and Block $\left(\mathrm{HT}_{0 \mathrm{~mm}}, \mathrm{p}=0.011\right.$; $\mathrm{HT}_{1 \mathrm{~mm}}, \mathrm{p}=0.004 ; \mathrm{HT}_{2 \mathrm{~mm}}, \mathrm{p}=0.008 ; \mathrm{HT}_{3 \mathrm{~mm}}, \mathrm{p}=0.013$ ) reached statistical significance. There were no statistically significant differences in the change of HT between Granulate + Pins and Block $\left(\mathrm{HT}_{0 \mathrm{~mm}}, \mathrm{p}=0.498 ; \mathrm{HT}_{1 \mathrm{~mm}}, \mathrm{p}=0.210 ; \mathrm{HT}_{2 \mathrm{~mm}}\right.$, $\mathrm{p}=0.216 ; \mathrm{HT}_{3 \mathrm{~mm}}, \mathrm{p}=0.362 ; \mathrm{HT}_{4 \mathrm{~mm}}, \mathrm{p}=0.913 ; \mathrm{HT}_{5 \mathrm{~mm}}, \mathrm{p}=0.760$ ) (Table 3 and Fig. 5).

The results regarding presence of voids within the augmented region are presented in Table 4. The majority of the voids were detected in Block group at $3 \mathrm{~mm}$ and 4 $\mathrm{mm}$ apical to the implant shoulder (Table 4). 


\section{Discussion}

In the present in vitro study, suturing of mucosal flaps after GBR of peri-implant bone defects induced a considerable displacement of particulated grafting material, resulting in a partial collapse of collagen membrane. The displacement of the grafting material and of the membrane was mostly pronounced in the coronal portion of the augmented site at the level of the implant shoulder. These results demonstrate that, even though a clinically tension-free flap closure was achieved in all cases, compressive forces on the coronal portion of the augmented site during suturing could not be totally avoided.

The use of fixation pins in combination with particulated bone substitute and collagen membrane and the application of block bone substitute with collagen membrane performed significantly better with regards to the dimensional stability of the augmented site, as compared to GBR by means of particulated bone substitute and collagen membrane. The additional use of fixation pins or the use of block instead of particulated grafting material permitted to reduce the amount of membrane collapse at the level of implant shoulder by more than $50 \%$ (from -1.1 $\mathrm{mm}$ to $-0.5 \mathrm{~mm}$ ). These results show that the stability of the augmented site can be enhanced either by stabilizing the barrier membrane or by providing adequate support to the membrane through a stable bone substitute.

In the present study, the use of pins for membrane fixation considerably facilitated the clinical handling during GBR. The adaptation of the membrane and the stabilization of the grafting material in the desired position were enhanced through the application of two fixation pins apical to the bone defect.

In a previous clinical study, GBR procedures with resorbable or non-resorbable membranes were performed with or without the use of polylactide pins (Carpio et al. 2000). When membrane fixation was provided, a significantly higher success of GBR was found in terms of frequency of postoperative complications and reduction in the size of the peri-implant defects, as compared to GBR without membrane fixation. There is, however, limited evidence available about the effect of the use of pins for membrane stabilization on the three-dimensional stability of jaw regions augmented by means of GBR (Benic \& Hämmerle 2014). Currently, the routine use 
of fixation pins is not generally recommended in combination with collagen membranes (Buser 2009).

In the present investigation, the use of block bone substitute for GBR was associated with an enhanced dimensional stability of the augmented site, as compared to GBR with particulated grafting material. The clinical handling of DBBM block was, however, frequently associated with intra-operative complications, such as block fracture during the preparation and the adaptation to the defect. In case of fracture, a new block was prepared. The frequent presence of voids within the augmented region in CBCT images can be explained by the difficulty in achieving an accurate fit of the block within the bone defect. DBBM blocks were not stabilized with fixation screws. The reduction of HT in the coronal region and the similar percentage of HT increase in the apical area can be explained by the rotation of the block within the defect. Moreover, this fact explains the occurrence of the outlier values of change in HT in the apical region of the defect and the increase in the frequency of voids for the Block procedure.

There are only limited clinical data reporting on the application of DBBM block in combination with collagen membrane for GBR. In a clinical study, DBBM blocks and collagen membranes were applied to 12 patients to treat horizontal bone defects before implant placement (Hämmerle et al. 2008). After 9-10 months, in 11 of 12 patients the resulting bone volume was sufficient to allow implant placement in the prosthetically optimal position. It was therefore concluded that the procedure was effective for horizontal ridge augmentation. These results are in agreement with a preclinical study comparing autogenous bone blocks with DBBM blocks for horizontal ridge augmentation, in which a similar increase of ridge augmentation was clinically measured in both groups (De Santis et al. 2012). In fact, 3 months after GBR all sites treated with DBBM blocks appeared, clinically, to be suitable for implant placement. Histologically, however, several studies found that DBBM blocks were mainly embedded in connective tissue and only a moderate amount of new bone formation was observed in peripheral parts of the graft (De Santis et al. 2012, Schwarz et al. 2008, Schwarz et al. 2010).

In the present trial, an attempt to mimic the clinical situation of implant placement with simultaneous GBR was done. An in vitro model based on box-shaped periimplant bone defects in pig mandibles was used for this purpose. The self-contained component of the peri-implant defect measured $1 \mathrm{~mm}$ in the bucco-oral direction. A small over-augmentation of the dehiscence defect is generally recommended when 
using particulated grafting material and non-stable membranes, to compensate for the displacement of parts of the grafting materials (Benic \& Hämmerle 2014). Bone substitutes were, therefore, applied in an attempt to achieve $1 \mathrm{~mm}$ of over-contour with respect to the buccal surface of the alveolar ridge.

A limitation of the present study was its in vitro set-up, which only partially simulated a clinical situation of GBR at peri-implant defects. Blood clot formation could not be reproduced in such an in vitro set-up. However, even though coagulation plays a role in the early healing, it cannot prevent the displacement of the bone substitute during wound closure. On the other hand, the in vitro model allowed standardizing the design of the mucosal flap, the morphology of the bone defect and the clinical procedures (e.g. amount of bone substitute, suturing technique). It was, therefore, possible to reduce the influence of confounding factors on the result of the procedures under investigation. Moreover, every site was treated once with each one of the three GBR procedures under investigation. This allowed further reducing the amount of the confounding factors, in particular the flap tension. Finally, one clinician, which was blinded and unaware of the aim of the study, performed the standardized wound closure in order to eliminate the operator's bias.

The clinical decision making regarding the choice of the optimal bone augmentation protocol and the selection of the materials is primarily based on the defect morphology and on whether or not the ridge contour needs to be augmented (Benic \& Hämmerle 2014). Based on the data of the present study, it can be deduced that a partial collapse of the barrier membrane can be expected for augmentations performed with particulated bone substitutes and collagen membrane. Therefore, when using particulated bone substitutes and non-stable membranes, an overaugmentation of the defect is recommended to compensate for material displacement. In situations requiring an enhanced stability of the augmented site, the use of pins for membrane stabilization is recommended. GBR by means of customized DBBM blocks is to be considered a promising approach to provide an adequate support of the membrane.

Further investigations are needed to examine the clinical implications of the findings of the present study. Future research should determine the need for augmentation procedures regarding the long-term success of the implants. In addition, the long-term stability of the augmented bone should be assessed and monitored. 


\section{Conclusions}

Within the limitations of the present in vitro study, it can be concluded that for GBR of peri-implant bone defects:

- Manipulation of mucosal flaps during suturing induced a displacement of bone substitute, resulting in a partial collapse of collagen membrane in the coronal portion of the augmented site.

- The primary stability of particulated bone substitute covered with collagen membrane was enhanced by applying pins for the fixation of the membrane.

- Block bone substitute in combination with collagen membrane performed significantly better than particulated bone substitute covered with collagen membrane in terms of dimensional stability of the augmented site during flap suturing. 


\section{Acknowledgements}

The investigators gratefully acknowledge Ph.D. Malgorzata Roos (Department of Biostatistics, University of Zurich, Zurich, Switzerland), Dr. Caroline Lustenberger (Clinic of Fixed and Removable Prosthodontics and Dental Material Science, Center of Dental Medicine, University of Zurich, Switzerland) and Ph.D. Eduard ValmasedaCastellón (Department of Oral Surgery and Implantology, University of Barcelona, Spain) for assistance in analyzing the data. This study was supported by the Clinic of Fixed and Removable Prosthodontics and Dental Material Science, Center of Dental Medicine, University of Zurich, Switzerland. The implants were kindly provided by DENTSPLY Implants, Mannheim, Germany. 


\section{Table legend}

Table 1a. Results of two-factor repeated measures ANOVA for horizontal thickness of the augmented region before suturing (baseline)

Table 1b. Results of two- and three-factor repeated measures ANOVA for horizontal thickness of the augmented region

Table 2. Results of horizontal thickness of the augmented region (HT) and change in HT at different apico-coronal levels for (a) Granulate, (b) Granulate + Pins and (c) Block procedures

Table 3. Results of change in horizontal thickness of the augmented region for different treatment procedures together with the results of repeated measures ANOVA

Table 4. Frequency of appearance of voids $\geq 0.5 \mathrm{~mm}$ within the augmented region in $\mathrm{CBCT}$ images 


\section{Figure legend}

Fig. 1. (a) Buccal and (b) occlusal view of the experimental peri-implant bone defect

Fig. 2. (a) Particulated xenograft applied for the Granulate and the Granulate + Pins treatment modalities. (b) Block xenograft used for the Block treatment modality. (c) Collagen membrane applied for the Granulate and the Block treatment modalities. (d) Collagen membrane stabilized by two titanium pins used for the Granulate + Pins treatment modality. (e) Buccal view after suturing.

Fig. 3. Bucco-oral $\mathrm{CBCT}$ reconstructions with the measurements of the dimensions of the augmented regions $\left(\mathrm{HT}_{0 \mathrm{~mm}}-\mathrm{HT}_{5 \mathrm{~mm}}\right)$. (a) Granulate, (b) Granulate + Pins and (c) Block treatment procedures before suturing. (d) Granulate, (e) Granulate + Pins and (f) Block treatment procedures after suturing.

Fig. 4. Bar plots representing the horizontal thicknesses of the augmented regions at different apico-coronal levels $\left(\mathrm{HT}_{0 \mathrm{~mm}}-\mathrm{HT}_{5 \mathrm{~mm}}\right)$ before and after suturing for (a) Granulate, (b) Granulate + Pins and (c) Block treatment procedures.

Fig. 5. Box plots representing the changes of horizontal thicknesses of the augmented regions during suturing for Granulate, Granulate + Pins and Block treatment procedures (a) in $\mathrm{mm}$ and (b) in $\% . \circ$ and ${ }^{*}$ in the figure represent the outliers. One outlier value of $\mathrm{HT}_{5 \mathrm{~mm}}$ for the Block procedure is not represented. 


\section{REFERENCES}

Becker, W., Becker, B.E., Handelsman, M., Ochsenbein, C. \& Albrektsson, T. (1991) Guided tissue regeneration for implants placed into extraction sockets: a study in dogs. Journal of Periodontology 62:703-709.

Benic, G.I., Jung, R.E., Siegenthaler, D.W. \& Hammerle, C.H. (2009) Clinical and radiographic comparison of implants in regenerated or native bone: 5-year results. Clinical Oral Implants Research 20:507-513.

Benic, G.I, Sancho-Puchades. M., Jung, R.E., Deyhle, H. \& Hämmerle, C.H. (2013) In vitro assessment of artifacts induced by titanium dental implants in cone beam computed tomography. Clinical Oral Implants Research 24:378-383.

Benic, G.I. \& Hammerle, C.H. (2014) Horizontal bone augmentation by means of guided bone regeneration. Periodontology 2000 Accepted for publication.

Buser, D. (2009) Implant placement with simultaneous guided bone regeneration: selection of biomaterials and surgical principles. In: Buser, D., editor. 20 years of guided bone regeneration in implant dentistry, $2^{\text {nd }}$ edition, p. 128 . Chicago: Quintessence Books.

Carpio, L., Loza, J., Lynch, S. \& Genco, R. (2000) Guided bone regeneration around endosseous implants with anorganic bovine bone mineral. A randomized controlled trial comparing bioabsorbable versus non-resorbable barriers. Journal of Periodontology 71:1743-1749.

Chiapasco, M. \& Zaniboni, M. (2009) Clinical outcomes of GBR procedures to correct peri-implant dehiscences and fenestrations: a systematic review. Clinical Oral Implants Research 20:113-123.

De Santis, E., Lang, N.P., Scala, A., Vigano, P., Salata, L.A. \& Botticelli, D. (2012) Healing outcomes at implants installed in grafted sites: an experimental study in dogs. Clinical Oral Implants Research 23:340-350. 
Hammerle, C.H., Jung, R.E., Yaman, D. \& Lang, N.P. (2008) Ridge augmentation by applying bioresorbable membranes and deproteinized bovine bone mineral: a report of twelve consecutive cases. Clinical Oral Implants Research 19:19-25.

Jensen, S.S. \& Terheyden, H. (2009) Bone augmentation procedures in localized defects in the alveolar ridge: clinical results with different bone grafts and bonesubstitute materials. The International Journal of Oral \& Maxillofacial Implants 24 (Suppl):218-236.

Jung, R.E., Fenner, N., Zitzmann, N.U. \& Hammerle, C.H. (2013) Long-term outcome of implants placed with guided bone regeneration (GBR) using resorbable and non-resorbable membranes after 12 to 14 years. Clinical Oral Implants Research 24: 1065-1073.

Kohal, R.J., Trejo, P.M., Wirsching, C., Hurzeler, M.B. \& Caffesse, R.G. (1999) Comparison of bioabsorbable and bioinert membranes for guided bone regeneration around non-submerged implants. An experimental study in the mongrel dog.

Clinical Oral Implants Research 10:226-237.

Lorenzoni, M., Pertl, C., Keil, C. \& Wegscheider, W.A. (1998) Treatment of periimplant defects with guided bone regeneration: a comparative clinical study with various membranes and bone grafts. The International Journal of Oral \& Maxillofacial Implants 13:639-646.

Mayfield, L., Skoglund, A., Nobreus, N. \& Attstrom, R. (1998) Clinical and radiographic evaluation, following delivery of fixed reconstructions, at GBR treated titanium fixtures. Clinical Oral Implants Research 9:292-302.

Mellonig, J.T., Nevins, M. \& Sanchez, R. (1998) Evaluation of a bioabsorbable physical barrier for guided bone regeneration. Part I. Material alone. The International Journal of Periodontics \& Restorative Dentistry 18:139-149.

Palmer, R.M., Smith, B.J., Palmer, P.J., Floyd, P.D., Johannson, C.B. \& Albrektsson T. (1998) Effect of loading on bone regenerated at implant dehiscence sites in humans. Clinical Oral Implants Research 9:283-291.

Schwarz, F., Herten, M., Ferrari, D., Wieland, M., Schmitz, L., Engelhardt, E. \& Becker, J. (2007) Guided bone regeneration at dehiscence-type defects using biphasic hydroxyapatite + beta tricalcium phosphate (Bone Ceramic) or a collagen- 
coated natural bone mineral (BioOss Collagen): an immunohistochemical study in dogs. International Journal of Oral and Maxillofacial Surgery 36:1198-1206.

Schwarz, F., Rothamel, D., Herten, M., Ferrari, D., Sager, M. \& Becker, J. (2008) Lateral ridge augmentation using particulated or block bone substitutes biocoated with rhGDF-5 and rhBMP-2: an immunohistochemical study in dogs. Clinical Oral Implants Research 19:642-52.

Schwarz, F., Ferrari, D., Balic, E., Buser, D., Becker, J. \& Sager, M. (2010) Lateral ridge augmentation using equine- and bovine-derived cancellous bone blocks: a feasibility study in dogs. Clinical Oral Implants Research 21:904-912.

Strietzel, F.P., Khongkhunthian, P., Khattiya, R., Patchanee, P. \& Reichart, P.A. (2006) Healing pattern of bone defects covered by different membrane types--a histologic study in the porcine mandible. Journal of biomedical materials research Part B. Applied Biomaterials 78:35-46.

Tan, W.L., Wong, T.L., Wong, M.C. \& Lang, N.P. (2012) A systematic review of post-extractional alveolar hard and soft tissue dimensional changes in humans. Clinical Oral Implants Research 23 (5 Suppl):1-21.

Von Arx, T., Cochran, D.L., Hermann, J.S., Schenk, R.K. \& Buser D. (2001) Lateral ridge augmentation using different bone fillers and barrier membrane application. A histologic and histomorphometric pilot study in the canine mandible. Clinical Oral Implants Research 12:260-269.

Warrer, L., Gotfredsen, K., Hjorting-Hansen, E. \& Karring, T. (1991) Guided tissue regeneration ensures osseointegration of dental implants placed into extraction sockets. An experimental study in monkeys. Clinical Oral Implants Research 2:166171.

Wilson, T.G.Jr., Schenk, R., Buser, D. \& Cochran, D. (1998) Implants placed in immediate extraction sites: a report of histologic and histometric analyses of human biopsies. The International Journal of Oral \& Maxillofacial Implants 13:333341. 
Zellin, G., Gritli-Linde, A. \& Linde, A. (1995) Healing of mandibular defects with different biodegradable and non-biodegradable membranes: an experimental study in rats. Biomaterials 16:601-609.

Zitzmann, N.U., Schärer, P. \& Marinello, C.P. (1999) Factors influencing the success of GBR. Smoking, timing of implant placement, implant location, bone quality and provisional restoration. Journal of Clinical Periodontology 26; 673-682

Zitzmann, N.U., Schärer, P., Marinello, C.P. (2001) Long-term results of implants treated with guided bone regeneration: a 5-year prospective study. The International Journal of Oral \& Maxillofacial Implants 16:355-366.

Zumstein, T., Billstrom, C. \& Sennerby, L. (2012) A 4- to 5-Year Retrospective Clinical and Radiographic Study of Neoss Implants Placed with or without GBR Procedures. Clinical Implant Dentistry and Related Research 14: 480-490. 

Figure 1

a)

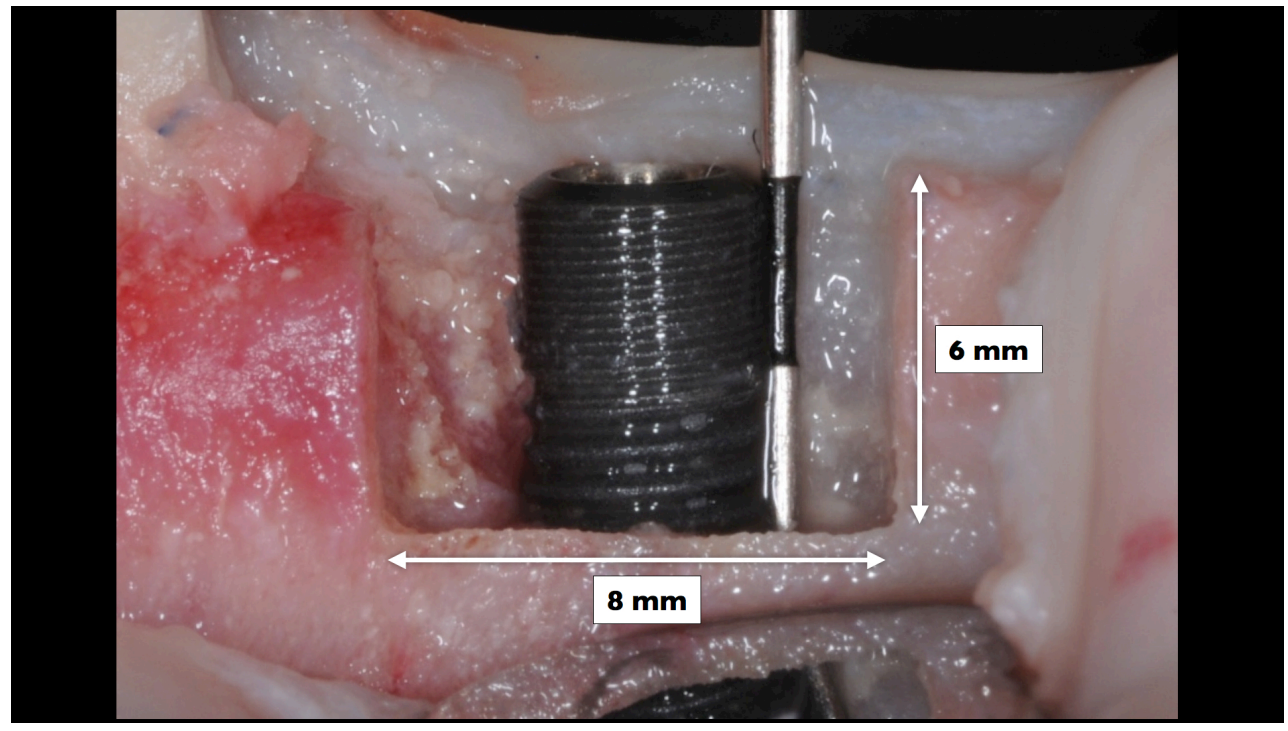

b)

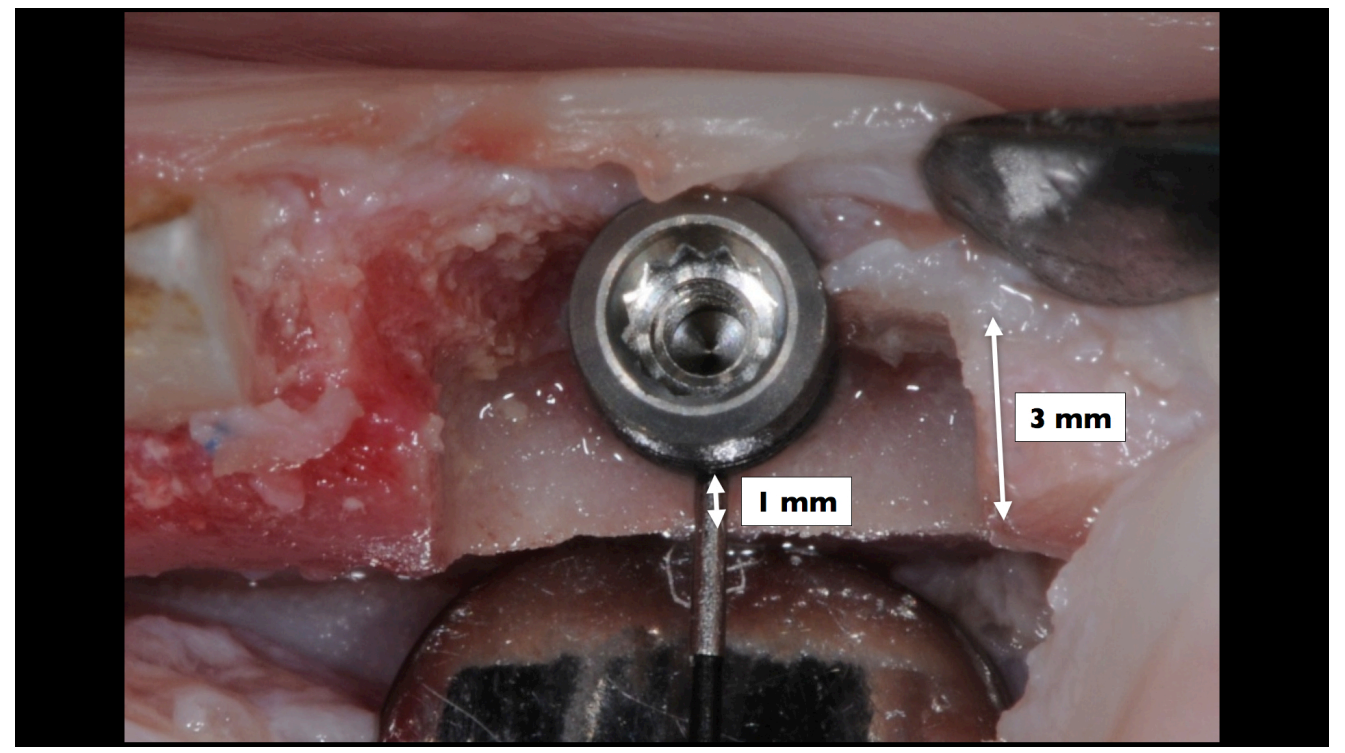


Figure 2

a)

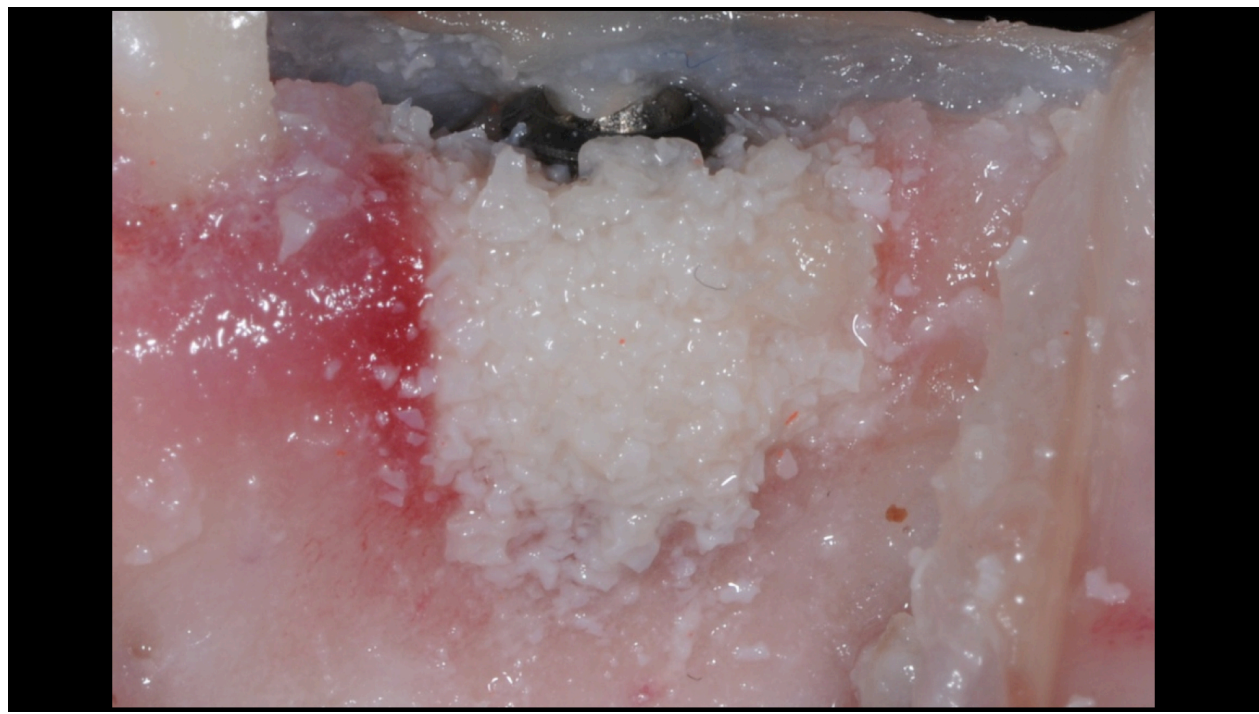

b)

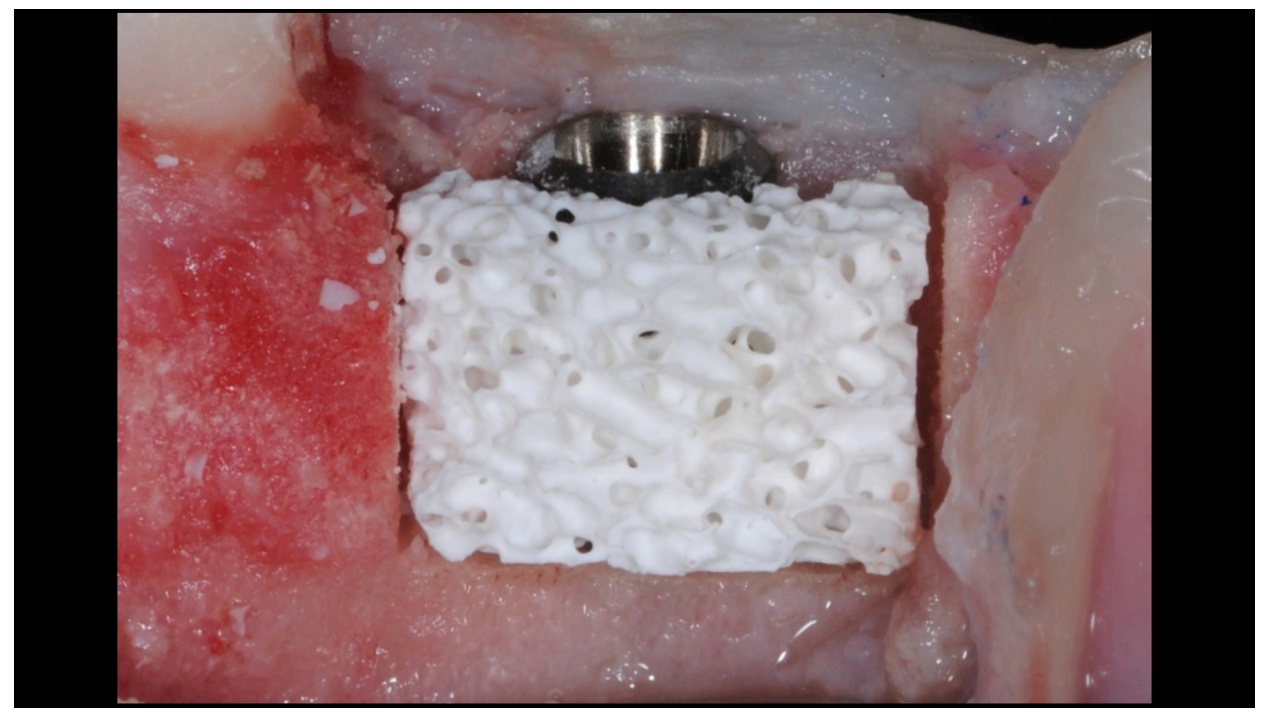

c)

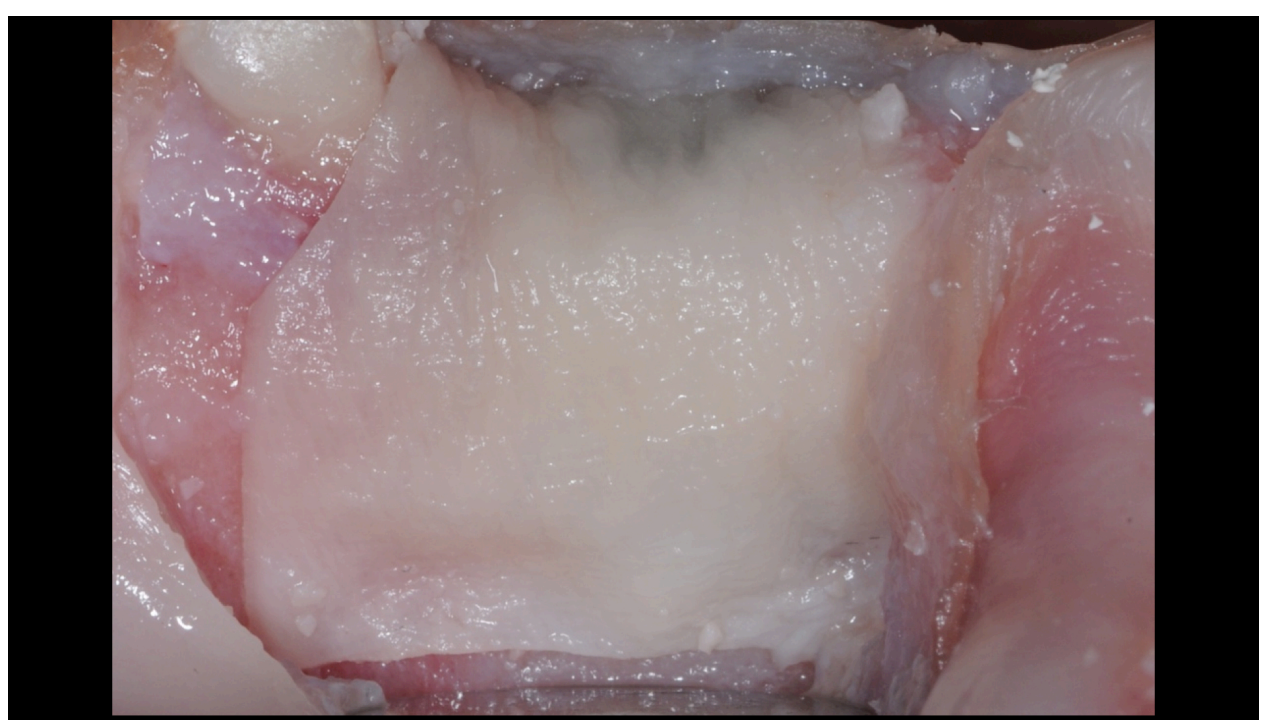


d)

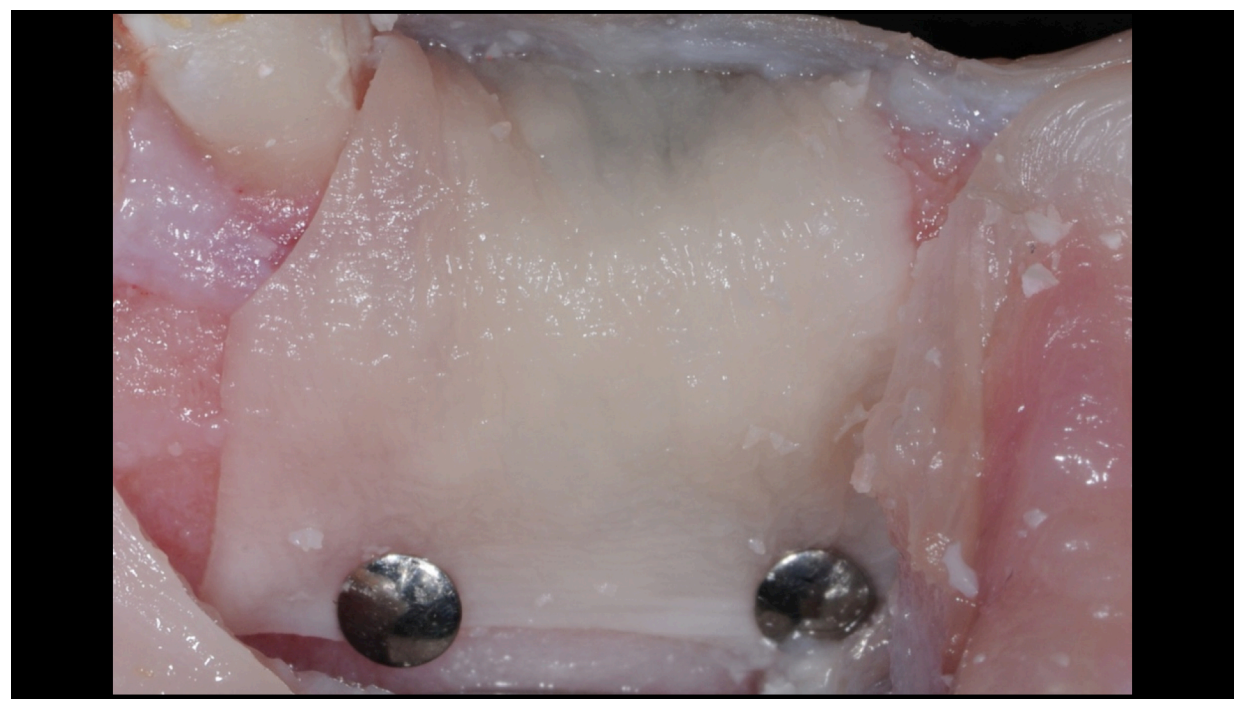

e)

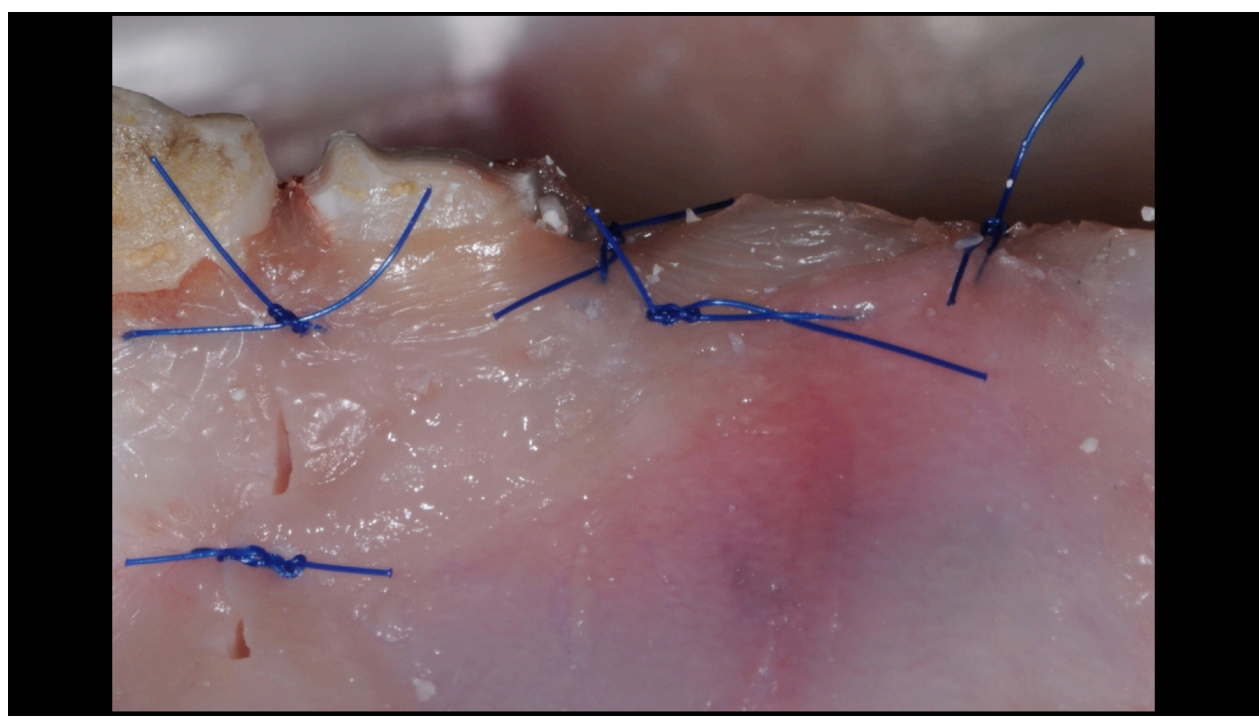


Figure 3

a)

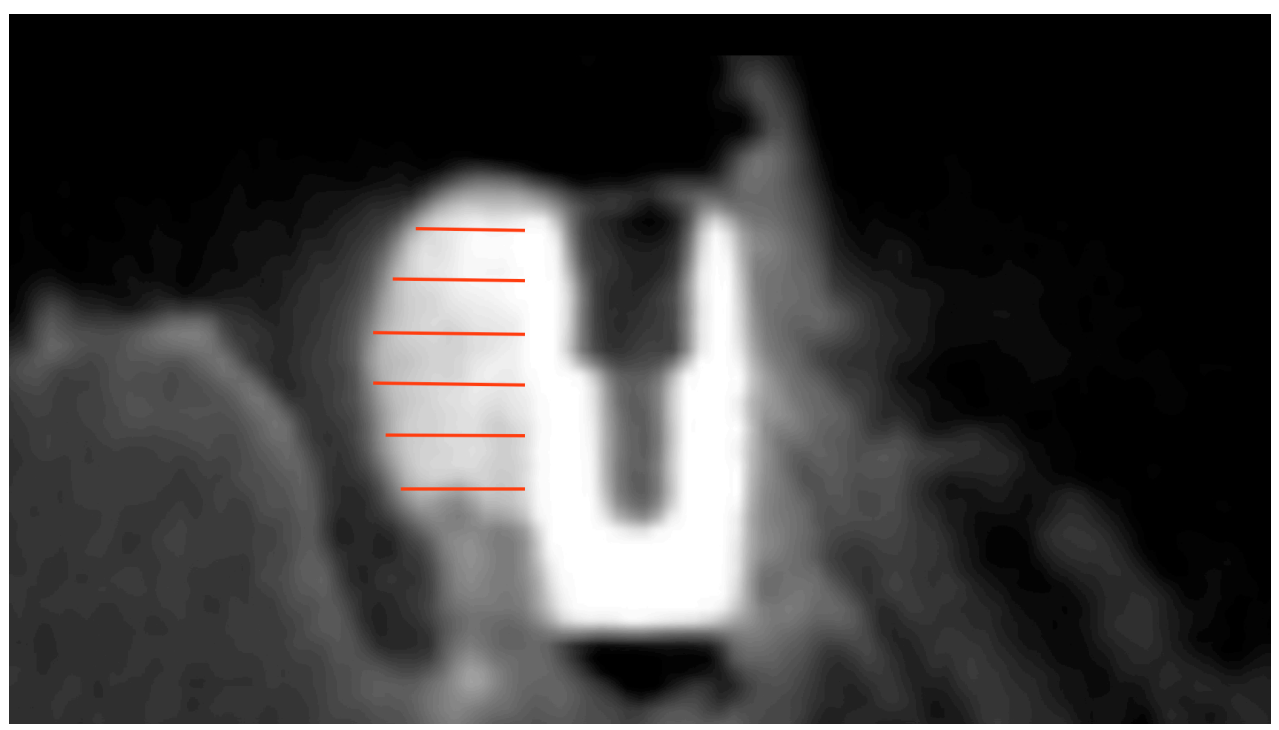

b)

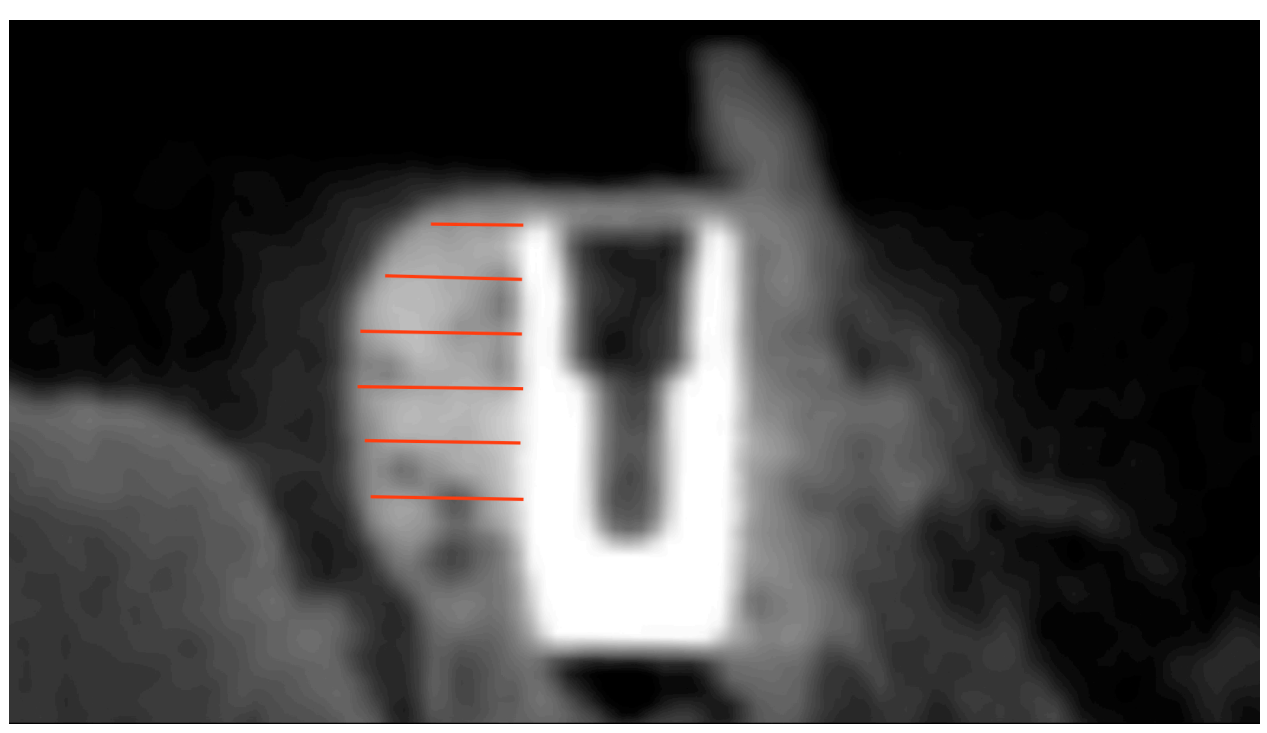

c)

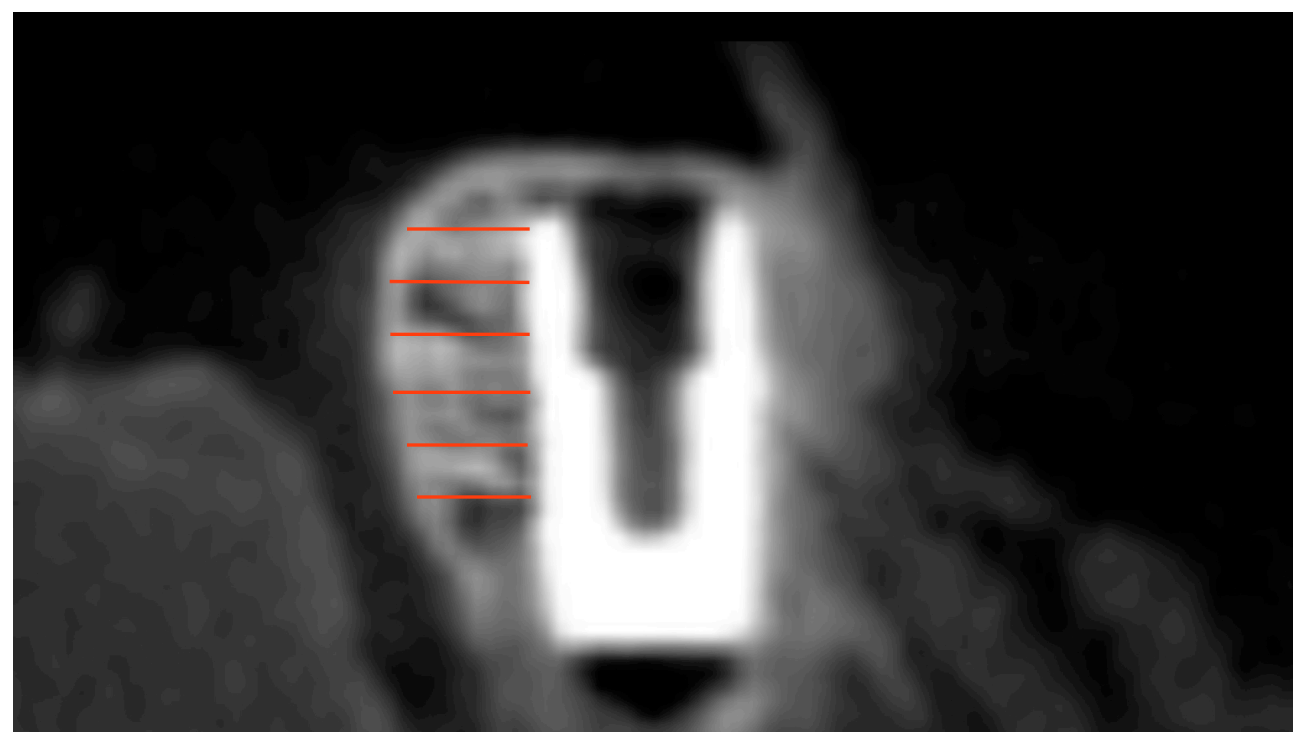


d)

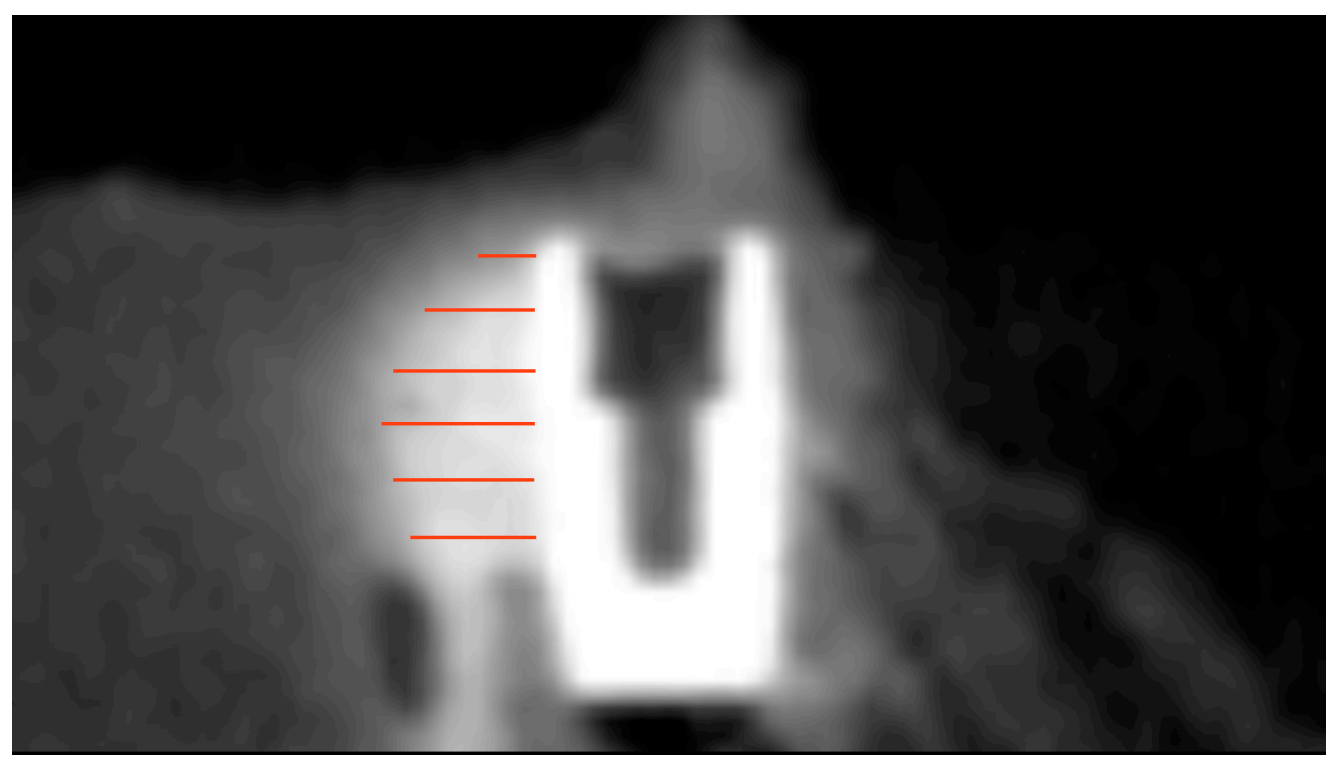

e)

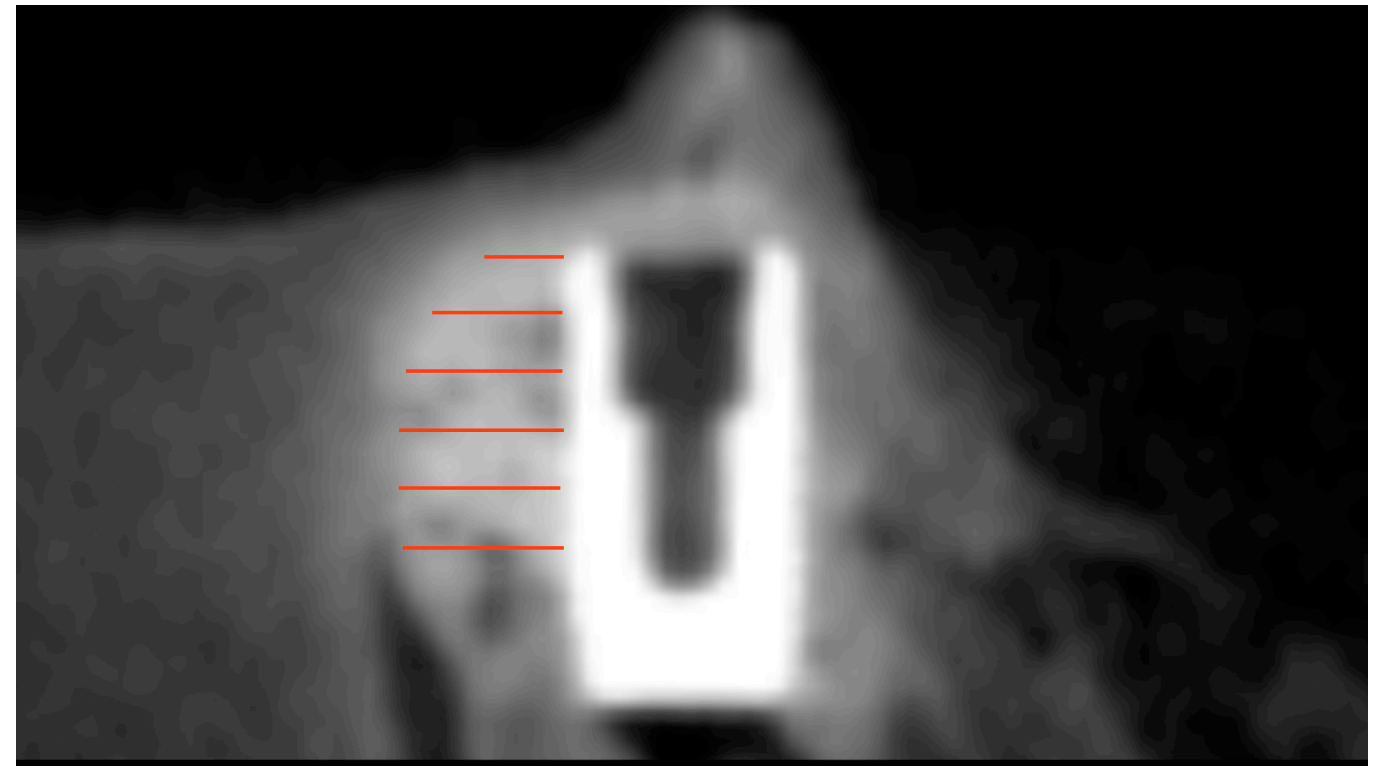

f)

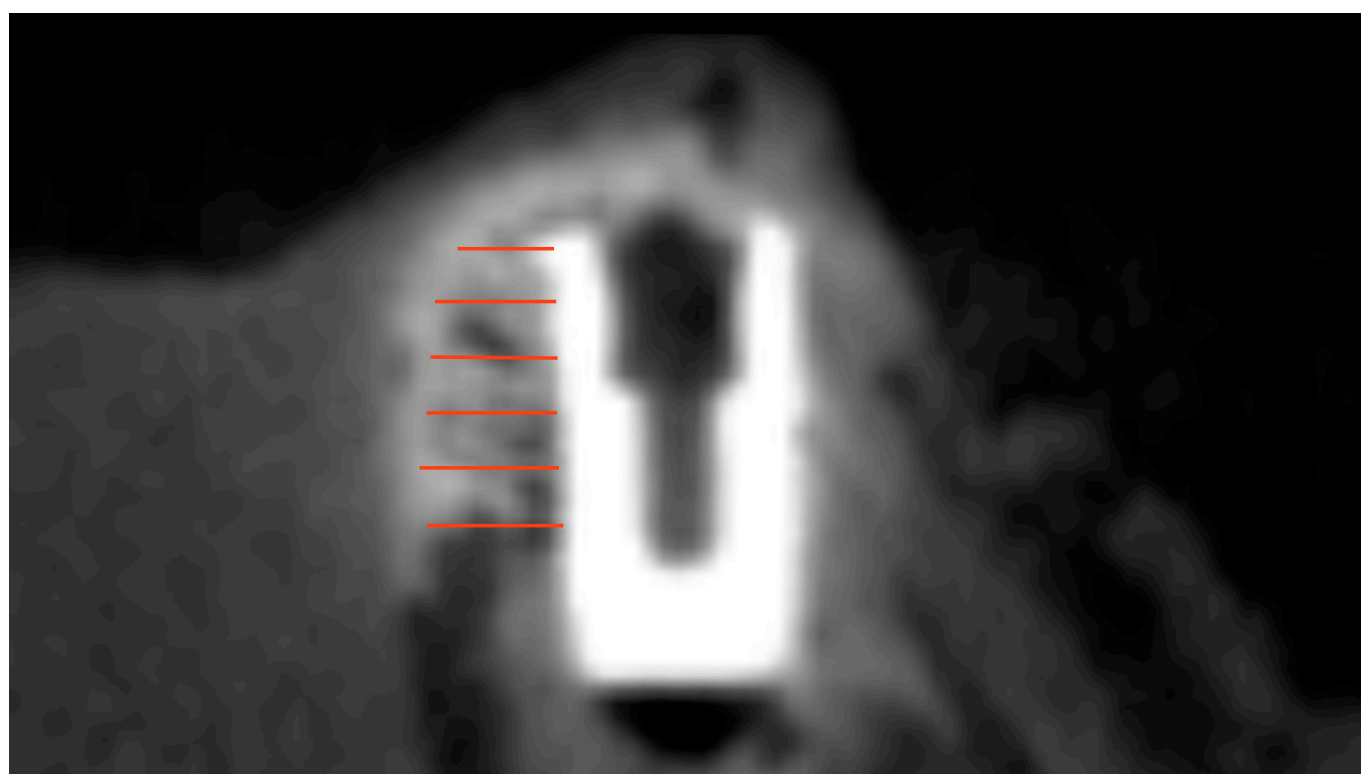




\section{Figure 4}

a)

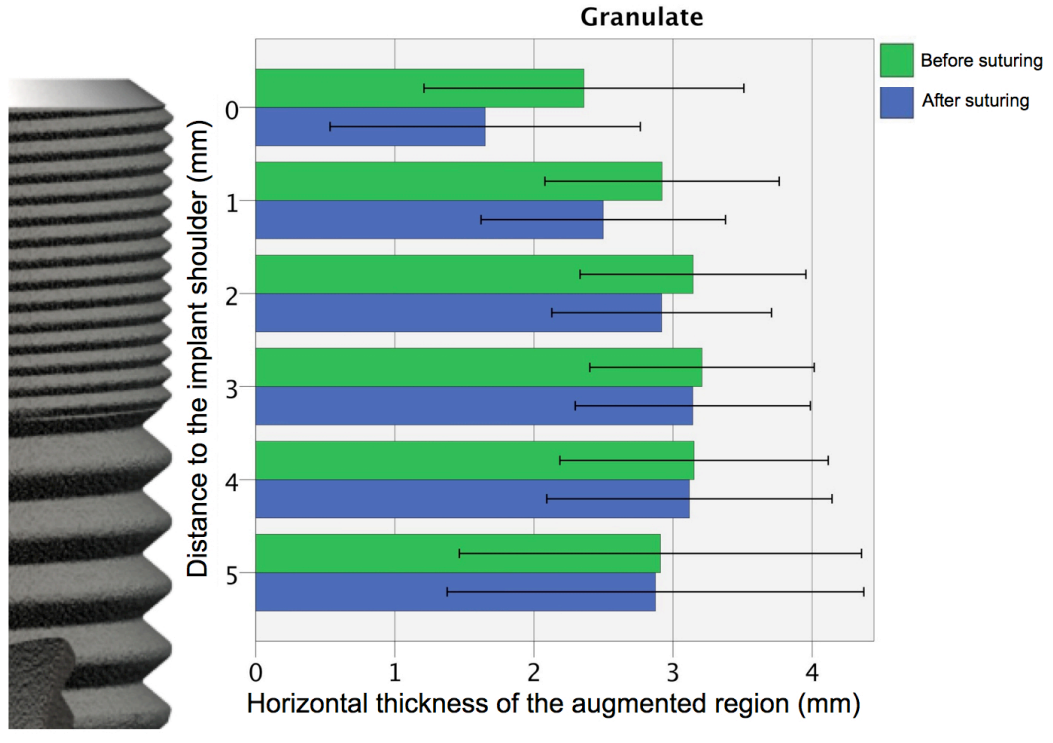

b)

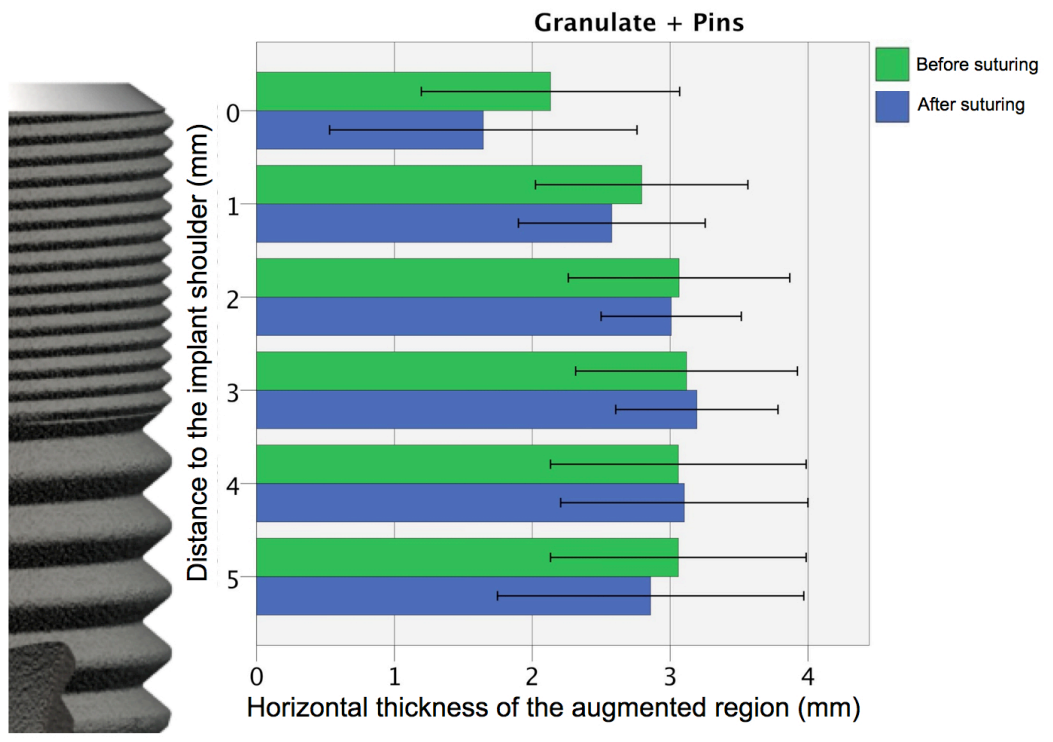

c)

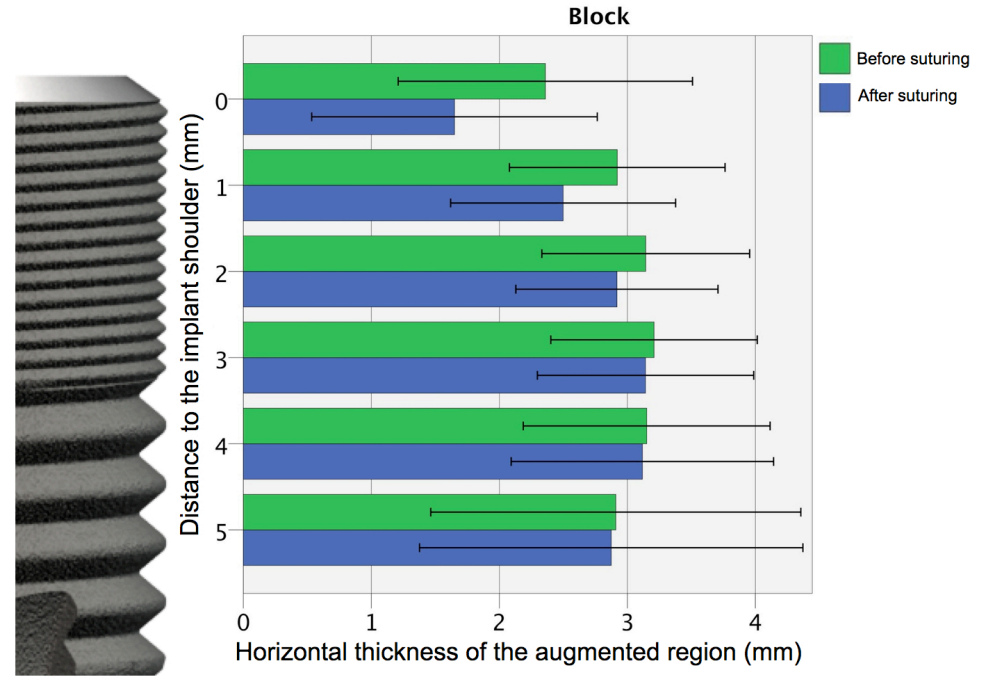


Figure 5

a)

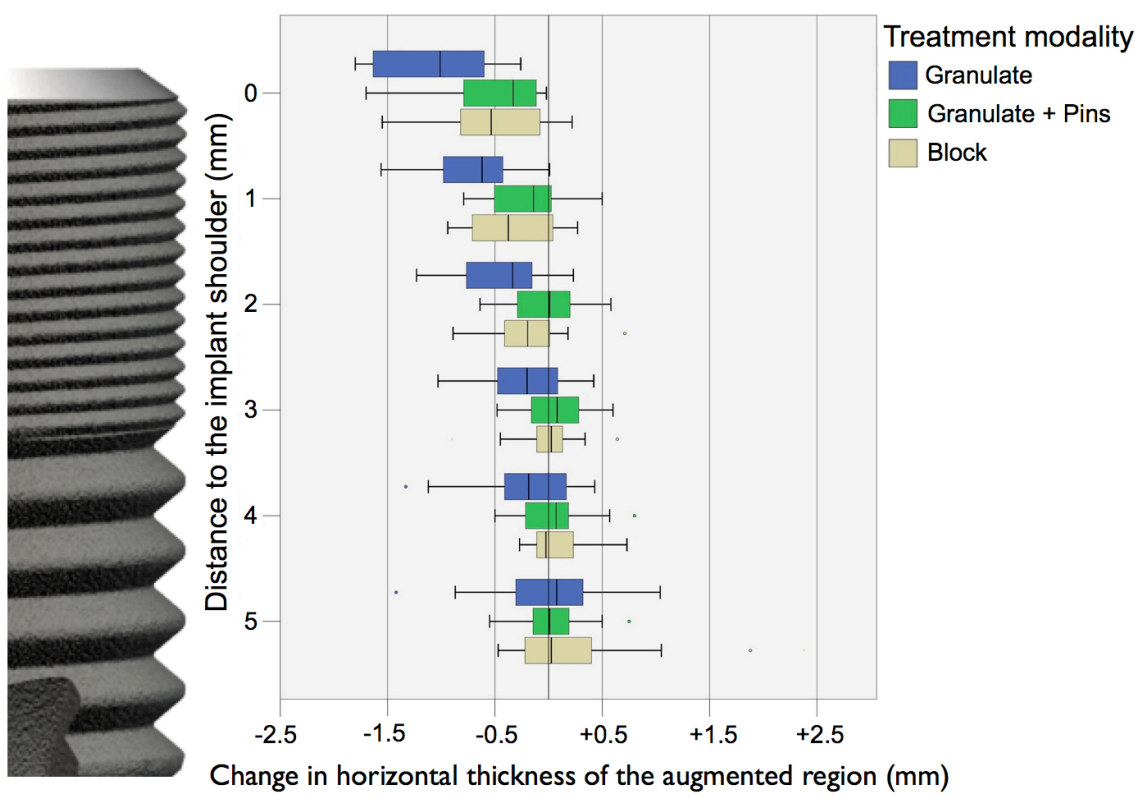

b)

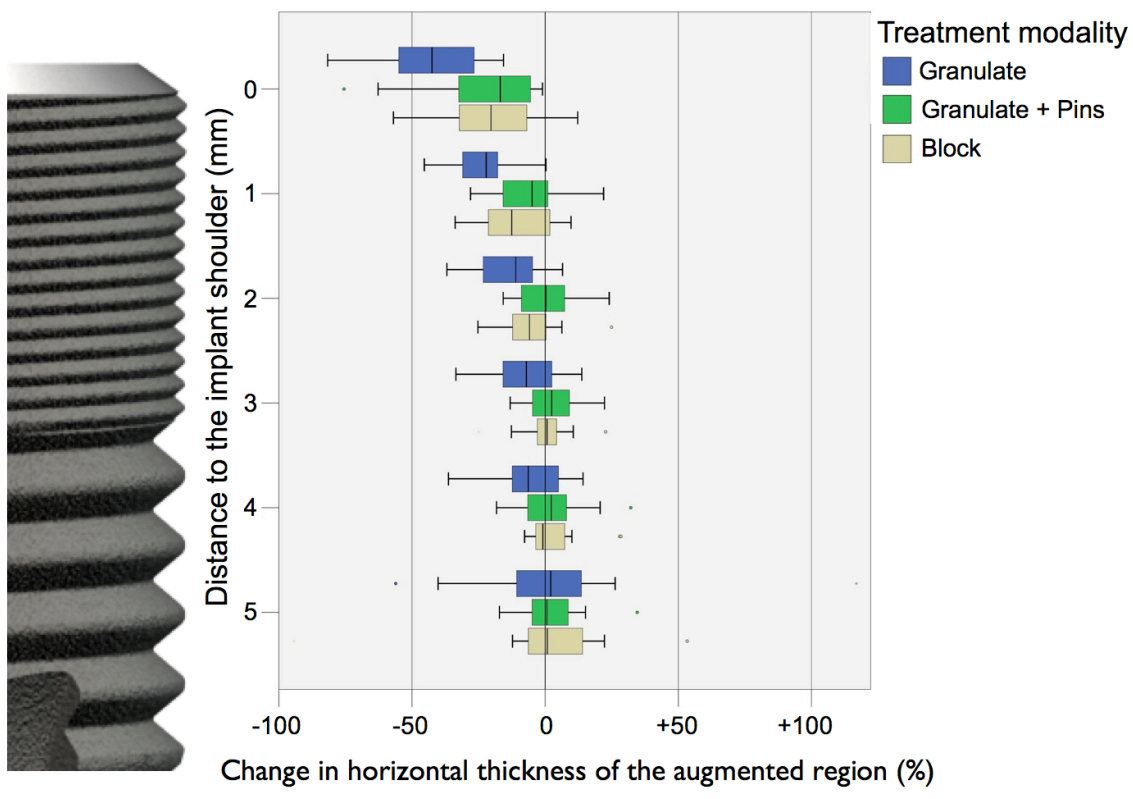


Table 1

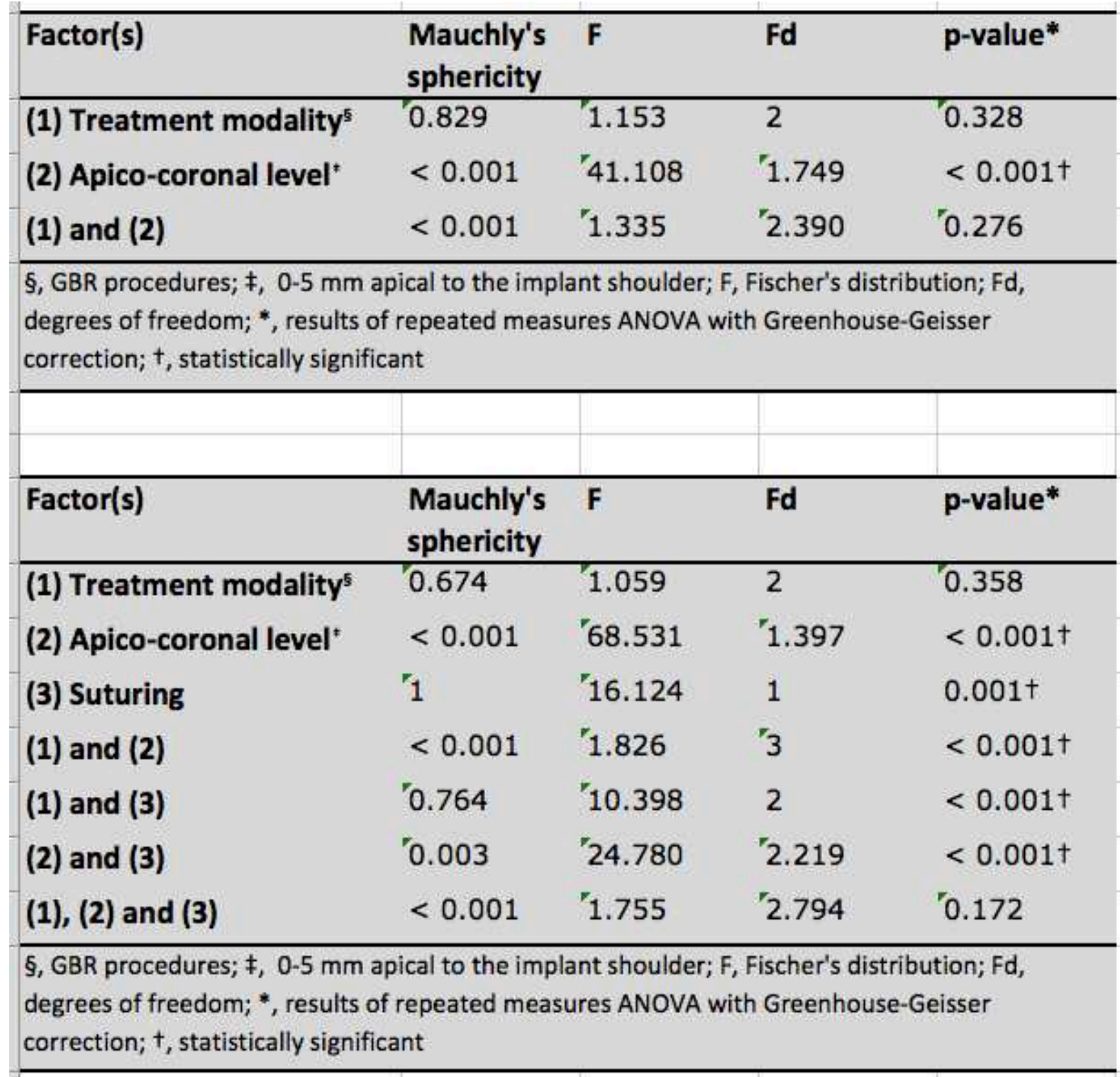


Table 2

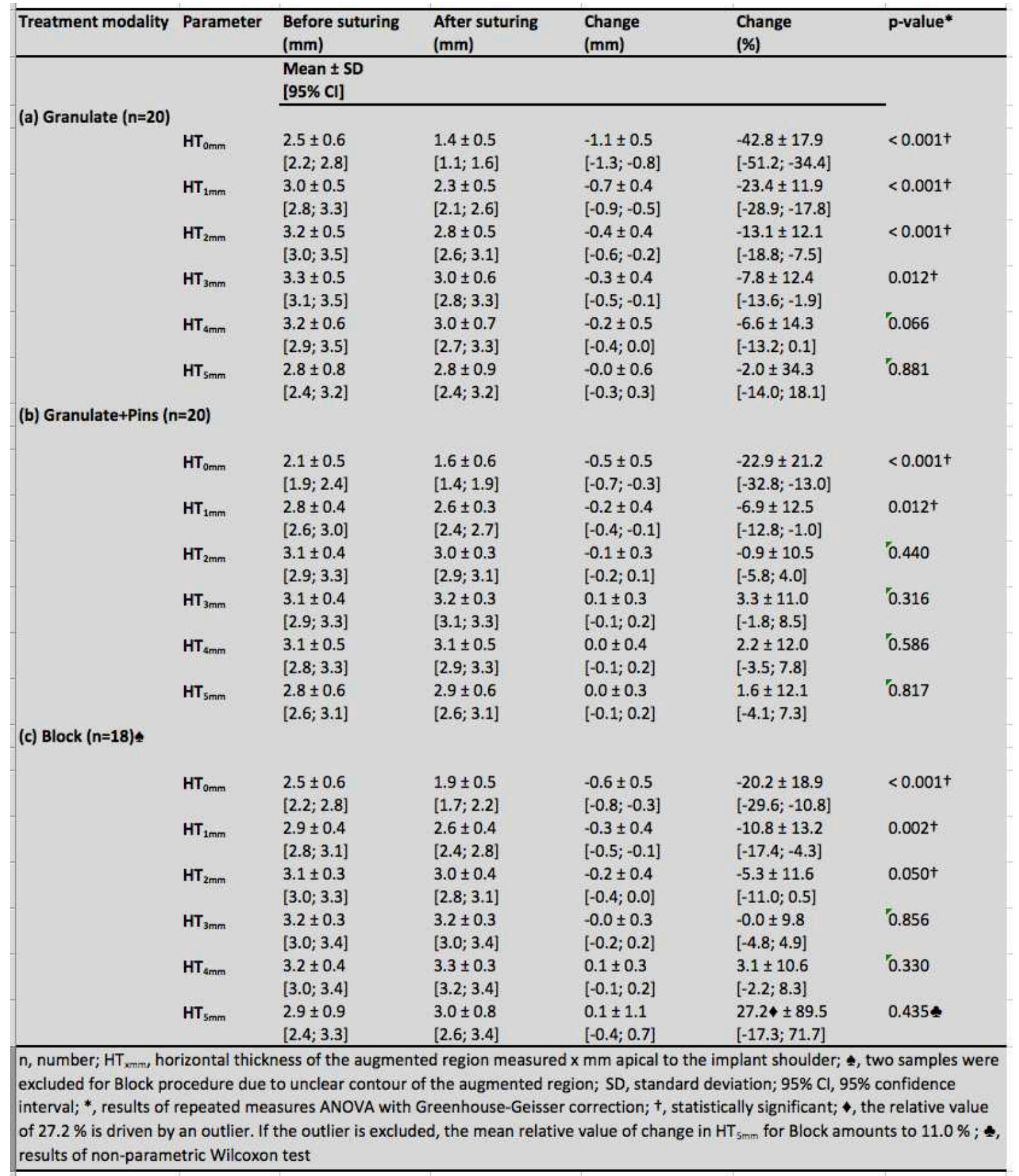




\section{Table 3}

\begin{tabular}{|c|c|c|c|c|c|c|c|}
\hline & \multicolumn{3}{|c|}{ Change (mm) } & \multicolumn{3}{|c|}{ Change (\%) } & \multirow[b]{2}{*}{ Statistical analysis* } \\
\hline & \multirow{2}{*}{$\begin{array}{l}\text { Granulate (G) } \\
\text { Mean } \pm \text { SD } \\
{[95 \% \mathrm{Cl}]}\end{array}$} & \multicolumn{2}{|c|}{ Granulate+Pins (P Block (B) } & \multirow[t]{2}{*}{ Granulate (G) } & \multicolumn{2}{|c|}{ Granulate+Pins (P) Block (B) } & \\
\hline & & & & & & & \multirow[b]{2}{*}{$\begin{array}{l}\text { G vs } P: p<0.001 \\
\text { G vs } B: p=0.011 \\
\text { P vs } B: p=0.498\end{array}$} \\
\hline $\mathrm{HT}_{\mathrm{omm}}$ & $\begin{array}{l}-1.1 \pm 0.5 \\
{[-1.3 ;-0.8]}\end{array}$ & $\begin{array}{l}-0.5 \pm 0.4 \\
{[-0.7 ;-0.3]}\end{array}$ & $\begin{array}{l}-0.6 \pm 0.5 \\
{[-0.8 ;-0.3]}\end{array}$ & $\begin{array}{l}-42.8 \pm 17.9 \\
{[-51.2 ;-34.4]}\end{array}$ & $\begin{array}{l}-22.9 \pm 21.2 \\
{[-32.8 ;-13.0]}\end{array}$ & $\begin{array}{l}-20.2 \pm 18.9 \\
{[-29.6 ;-10.8]}\end{array}$ & \\
\hline $\mathrm{HT}_{1 \mathrm{~mm}}$ & $\begin{array}{l}-0.7 \pm 0.4 \\
{[-0.9 ;-0.5]}\end{array}$ & $\begin{array}{l}-0.2 \pm 0.4 \\
{[-0.4 ;-0.1]}\end{array}$ & $\begin{array}{l}-0.3 \pm 0.4 \\
{[-0.5 ;-0.1]}\end{array}$ & $\begin{array}{l}-23.4 \pm 11.9 \\
{[-28.9 ;-17.8]}\end{array}$ & $\begin{array}{l}-6.9 \pm 12.5 \\
{[-12.8 ;-1.0]}\end{array}$ & $\begin{array}{l}-10.8 \pm 13.2 \\
{[-17.4 ;-4.3]}\end{array}$ & $\begin{array}{l}\text { G vs } P: p<0.001+ \\
\text { G vs } B: p=0.004+ \\
P \text { vs } B: p=0.210\end{array}$ \\
\hline $\mathrm{HT}_{2 \mathrm{~mm}}$ & $\begin{array}{l}-0.4 \pm 0.4 \\
{[-0.6 ;-0.2]}\end{array}$ & $\begin{array}{l}-0.1 \pm 0.3 \\
{[-0.2 ; 0.1]}\end{array}$ & $\begin{array}{l}-0.2 \pm 0.4 \\
{[-0.4 ; 0.0]}\end{array}$ & $\begin{array}{l}-13.1 \pm 12.1 \\
{[-18.8 ;-7.5]}\end{array}$ & $\begin{array}{l}-0.9 \pm 10.5 \\
{[-5.8 ; 4.0]}\end{array}$ & $\begin{array}{l}-5.3 \pm 11.6 \\
{[-11.0 ; 0.5]}\end{array}$ & $\begin{array}{l}\text { G vs } P: p=0.001+ \\
\text { G vs } B: p=0.008+ \\
\text { P vs B: } p=0.216\end{array}$ \\
\hline $\mathrm{HT}_{3 \mathrm{~mm}}$ & $\begin{array}{l}-0.3 \pm 0.4 \\
{[-0.5 ;-0.1]}\end{array}$ & $\begin{array}{l}0.1 \pm 0.3 \\
{[-0.1 ; 0.2]}\end{array}$ & $\begin{array}{l}0.0 \pm 0.3 \\
{[-0.2 ; 0.2]}\end{array}$ & $\begin{array}{l}-7.8 \pm 12.4 \\
{[-13.6 ;-1.9]}\end{array}$ & $\begin{array}{l}3.3 \pm 11.0 \\
{[-1.8 ; 8.5]}\end{array}$ & $\begin{array}{l}0.0 \pm 9.8 \\
{[-4.8 ; 4.9]}\end{array}$ & $\begin{array}{l}\text { G vs } P: p=0.007^{+} \\
\text {G vs } B: p=0.013+ \\
\text { P vs } B: p=0.362\end{array}$ \\
\hline $\mathrm{HT}_{4 \mathrm{~mm}}$ & $\begin{array}{l}-0.2 \pm 0.5 \\
{[-0.4 ; 0.0]}\end{array}$ & $\begin{array}{l}0.0 \pm 0.4 \\
{[-0.1 ; 0.2]}\end{array}$ & $\begin{array}{l}0.1 \pm 0.3 \\
{[-0.1 ; 0.2]}\end{array}$ & $\begin{array}{l}-6.6 \pm 14.3 \\
{[-13.2 ; 0.1]}\end{array}$ & $\begin{array}{l}2.2 \pm 12.0 \\
{[-3.5 ; 7.8]}\end{array}$ & $\begin{array}{l}3.1 \pm 10.6 \\
{[-2.2 ; 8.3]}\end{array}$ & $\begin{array}{l}\text { G vs } P: p=0.132 \\
\text { G vs } B: p=0.034+ \\
P \text { vs } B: p=0.913\end{array}$ \\
\hline $\mathrm{HT}_{5 \mathrm{~mm}}$ & $\begin{array}{l}0.0 \pm 0.6 \\
{[-0.3 ; 0.3]}\end{array}$ & $\begin{array}{l}0.0 \pm 0.3 \\
{[-0.1 ; 0.2]}\end{array}$ & $\begin{array}{l}0.1 \pm 1.1 \\
{[-0.4 ; 0.7]}\end{array}$ & $\begin{array}{l}-2.0 \pm 34.3 \\
{[-14.0 ; 18.1]}\end{array}$ & $\begin{array}{l}1.6 \pm 12.1 \\
{[-4.1 ; 7.3]}\end{array}$ & $\begin{array}{l}27.2 \downarrow \pm 89.5 \\
{[-17.3 ; 71.7]}\end{array}$ & $\begin{array}{l}\text { G vs } P: p=0.867 \\
\text { G vs } B: p=0.862 \\
P \text { vs } B: p=0.760\end{array}$ \\
\hline$T_{x m m,}$ & $\begin{array}{l}\text { al thickness } \\
\text { rval; }{ }^{*} \text {, resu } \\
\text { by an outlie } \\
\text { coxon test }\end{array}$ & 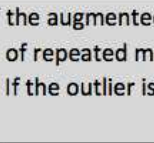 & (1) & ical to the im & ant shc & andard devi & $\begin{array}{l}5 \% \mathrm{Cl}, 95 \% \\
\text { the relative value of } \\
6 ; \% \text {, results of non- }\end{array}$ \\
\hline
\end{tabular}

Table 4

\begin{tabular}{|c|c|c|c|c|c|c|}
\hline \multirow[b]{2}{*}{$\begin{array}{l}\text { Apico-coronal } \\
\text { level* }\end{array}$} & \multicolumn{2}{|c|}{ Granulate } & \multicolumn{2}{|c|}{ Granulate+Pins } & \multicolumn{2}{|c|}{ Block } \\
\hline & $\begin{array}{l}\text { Before } \\
\text { suturing }\end{array}$ & $\begin{array}{l}\text { After } \\
\text { suturing }\end{array}$ & $\begin{array}{l}\text { Before } \\
\text { suturing }\end{array}$ & $\begin{array}{l}\text { After } \\
\text { suturing }\end{array}$ & $\begin{array}{l}\text { Before } \\
\text { suturing }\end{array}$ & After suturing \\
\hline $0 \mathrm{~mm}$ & $0 \%(0 / 20)$ & $0 \%(0 / 20)$ & $0 \%(0 / 20)$ & $0 \%(0 / 20)$ & $0 \%(0 / 20)$ & $0 \%(0 / 20)$ \\
\hline $1 \mathrm{~mm}$ & $5 \%(1 / 20)$ & $0 \%(0 / 20)$ & $0 \%(0 / 20)$ & $0 \%(0 / 20)$ & $0 \%(0 / 20)$ & $0 \%(0 / 20)$ \\
\hline $2 \mathrm{~mm}$ & $0 \%(0 / 20)$ & $0 \%(0 / 20)$ & $5 \%(1 / 20)$ & $0 \%(0 / 20)$ & $0 \%(0 / 20)$ & $5 \%(1 / 20)$ \\
\hline $3 \mathrm{~mm}$ & $10 \%(2 / 20)$ & $0 \%(0 / 20)$ & $0 \%(0 / 20)$ & $0 \%(0 / 20)$ & $20 \%(4 / 20)$ & $35 \%(7 / 20)$ \\
\hline $4 \mathrm{~mm}$ & $5 \%(1 / 20)$ & $0 \%(0 / 20)$ & $5 \%(1 / 20)$ & $0 \%(0 / 20)$ & $15 \%(3 / 20)$ & $25 \%(5 / 20)$ \\
\hline $5 \mathrm{~mm}$ & $0 \%(0 / 20)$ & $0 \%(0 / 20)$ & $0 \%(0 / 20)$ & $0 \%(0 / 20)$ & $0 \%(0 / 20)$ & $0 \%(0 / 20)$ \\
\hline
\end{tabular}

